OPEN ACCESS

Edited by:

Diana K. Sarko,

Southern Illinois University

Carbondale, United States

Reviewed by:

Michael Chopp,

Henry Ford Health System,

United States

Chiara Fenoglio,

University of Milan, Italy

Lynn Pulliam,

University of California,

San Francisco, United States

*Correspondence:

Vinay Parikh

vinay.parikh@temple.edu

${ }^{\dagger}$ Present address:

Michael R. Duggan,

Laboratory of Behavioral Neuroscience, National Institute on Aging, Baltimore, MD, United States

Specialty section:

This article was submitted to Neurocognitive Aging and Behavior, a section of the journal

Frontiers in Aging Neuroscience

Received: 13 December 2021

Accepted: 09 February 2022

Published: 01 March 2022

Citation:

Duggan MR, Lu A, Foster TC

Wimmer M and Parikh V (2022)

Exosomes in Age-Related Cognitive

Decline: Mechanistic Insights

and Improving Outcomes.

Front. Aging Neurosci. 14:834775.

doi: 10.3389/fnagi.2022.834775

\section{Exosomes in Age-Related Cognitive Decline: Mechanistic Insights and Improving Outcomes}

\author{
Michael R. Duggan ${ }^{1 \dagger}$, Anne Lu1 ${ }^{1}$, Thomas C. Foster ${ }^{2}$, Mathieu Wimmer ${ }^{1}$ and \\ Vinay Parikh ${ }^{1 *}$
}

${ }^{1}$ Department of Psychology and Neuroscience Program, Temple University, Philadelphia, PA, United States, ${ }^{2}$ Department of Neuroscience, University of Florida College of Medicine, Gainesville, FL, United States

Aging is the most prominent risk factor for cognitive decline, yet behavioral symptomology and underlying neurobiology can vary between individuals. Certain individuals exhibit significant age-related cognitive impairments, while others maintain intact cognitive functioning with only minimal decline. Recent developments in genomic, proteomic, and functional imaging approaches have provided insights into the molecular and cellular substrates of cognitive decline in age-related neuropathologies. Despite the emergence of novel tools, accurately and reliably predicting longitudinal cognitive trajectories and improving functional outcomes for the elderly remains a major challenge. One promising approach has been the use of exosomes, a subgroup of extracellular vesicles that regulate intercellular communication and are easily accessible compared to other approaches. In the current review, we highlight recent findings which illustrate how the analysis of exosomes can improve our understanding of the underlying neurobiological mechanisms that contribute to cognitive variation in aging. Specifically, we focus on exosome-mediated regulation of miRNAs, neuroinflammation, and aggregate-prone proteins. In addition, we discuss how exosomes might be used to enhance individual patient outcomes by serving as reliable biomarkers of cognitive decline and as nanocarriers to deliver therapeutic agents to the brain in neurodegenerative conditions.

Keywords: exosomes, aging, cognition, biomarkers, therapeutics

\section{INTRODUCTION}

Age-related cognitive decline remains a prominent public health concern, with Alzheimer's Disease (AD) accounting for the majority of dementia diagnoses (i.e., 60-80\%) (Alzheimer's Association, 2020). Despite the recent approval of an anti-amyloid biologic (i.e., aducanumab), it poses significant risks for side effects (e.g., microhemorrhages, edema), can be cost prohibitive due to the lack of insurance coverage and has not yet been shown to reliably mitigate cognitive decline (Alexander et al., 2021; Anderson et al., 2021; Knopman et al., 2021; Salloway et al., 2022). As alternative approved pharmacotherapies (i.e., AChE inhibitors and an NMDAR antagonist) can 
only ameliorate symptomology temporarily, there remains no treatment capable of preventing or curing $\mathrm{AD}$ and its associated cognitive decline (Bullain and Doody, 2020).

Aging is the most prominent risk factor for cognitive decline, but behavioral symptomology and underlying neurobiology can vary between individuals. Indeed, some individuals exhibit significant cognitive impairments in comparison to age-matched controls, while others maintain intact cognitive functioning or display only minimal decline (Wilson et al., 2002; Hayden et al., 2011). Although elderly individuals with poor cognitive performance are at a higher risk of developing age-related dementia including AD (Albert et al., 2001), examinations from comprehensive clinical samples indicate such age-related cognitive variation can occur independently from pathological manifestations (i.e., cognitive deficits without neuropathological hallmarks and vice versa) (Katzman et al., 1988; Morris et al., 1996; Balasubramanian et al., 2012; Negash et al., 2013; Kawas et al., 2015; Aiello Bowles et al., 2019). Furthermore, after accounting for known pathological measures, approximately half of the estimated variation in cognitive decline remains unexplained (Boyle et al., 2013, 2021). In fact, postmortem analyses now suggest the behavioral symptomology leading to dementia diagnosis is often accompanied by a mixture of neuropathological hallmarks (Schneider et al., 2007; Rahimi and Kovacs, 2014; James et al., 2016; White et al., 2016). While these results exemplify the need for a better understanding of the biological mechanisms that contribute to differing cognitive trajectories in aging, they also suggest opportunities to improve diagnostic indicators for cognitive decline associated with agerelated neurodegenerative disorders.

Several approaches have proved valuable for improving diagnostics and developing novel therapeutics. For one, the implementation of novel PET ligands over the past decade for $A \beta$ and Tau is now recognized as an important component in recently adopted $\mathrm{AD}$ criteria (Jack et al., 2016). However, the detection of abnormal protein aggregates via PET has several limitations, including its predictability with regard to behavioral symptomology over time (Jack et al., 2019). Furthermore, these methods are primarily utilized for screening participants or assessing endpoints in clinical trials, in part due to prohibitive costs not covered by insurance as well as a lack of standardized thresholds to differentiate between dementia stages (Mitka, 2013; Rice and Bisdas, 2017; Weigand et al., 2020). Along with PET imaging, genomic interrogations of large clinical cohorts have further substantiated the increased risk for cognitive decline among individuals with common (e.g., APOE, APP, PSEN1 etc.) as well as rare (e.g., TREM2, MS4A, SORL1 etc.) genetic variants (Lanoiselée et al., 2017; Deming et al., 2019; Yamazaki et al., 2019; Holstege et al., 2020). However, the application of these findings to improve patient outcomes requires further elucidation (Van Cauwenberghe et al., 2016; Patron et al., 2019; Novikova et al., 2021). In addition, the advent of advanced proteomic platforms has improved diagnostic capacity compared to clinical assessment, particularly for CSF and blood derived samples; however, these can sometimes rely on a limited set of molecular targets measured from a single time point and may not necessarily relay information regarding the causal, biological mechanisms that facilitate variation in cognitive functioning (Janelidze et al., 2020; Palmqvist et al., 2020; Thijssen et al., 2020). While these approaches can help identify individuals at risk for cognitive deficits in aging, one approach that is increasingly recognized to gain insights into the neurobiological mechanisms of cognitive decline while potentially improving individual outcomes is the analysis of extracellular vesicles, namely exosomes.

In the current review, we will highlight recent findings which illustrate how the analysis of exosomes can improve our knowledge of varying mechanisms underlying age-related cognitive decline. In addition, we will discuss how exosomes might be used to enhance individual patient outcomes by serving as reliable biomarkers and therapeutic agents for age-related neurodegenerative disorders.

\section{EXOSOMES}

Exosomes are membranous lipid compartments $(\sim 50-150 \mathrm{~nm})$ whose primary function is to translocate biological substrates (e.g., proteins, lipids, nucleic acids) between cells (Tkach and Thery, 2016; van Niel et al., 2018). Exosome biogenesis begins at the plasma membrane with the formation of earlysorting endosomes (ESEs). ESEs are formed when plasma membrane invagination encloses cell-surface proteins and other proximal molecules in the extracellular environment. These may combine with existing ESEs, while the Golgi and ER can also contribute to their contents (Hessvik and Llorente, 2018; van Niel et al., 2018; Mathieu et al., 2019). ESEs can eventually develop into late-sorting endosomes (LSEs), whose further inward invagination generates multivesicular bodies (MVBs) that contain intraluminal vesicles (ILVs). From here, MVBs can either fuse with lysosomes or autophagosomes for degradation, or fuse with the plasma membrane for extracellular release of ILVs, which become de facto exosomes upon exiting the cell (Gurunathan et al., 2019). While the exact processes governing their intercellular transport remain debated, exosomes can be internalized through several distinct mechanisms, including clathrin-dependent endocytosis and phagocytosis, which results in the release of exosomal contents in recipient cells (Mulcahy et al., 2014). Of note, the current article will primarily focus on exosomes, rather than on extracellular vesicles (EVs), which is a general term used to describe different subtypes of vesicles based on their size, content, and function, including exosomes, microvesicles (MVEs), and apoptotic bodies. For example, although exosomes are routinely classified alongside MVEs, their biogenesis is thought to utilize distinct cellular mechanisms (i.e., outward budding and fission of the plasma membrane) (Tricarico et al., 2017). Regarding nomenclature, the current review will utilize the terminology of exosome throughout, since the literature cited herein uses the term exosome or small EV when referring to the same type of vesicle; however, guidelines suggest that the later term is the appropriate generic term (Théry et al., 2018).

Exosome production, release and uptake is thought be conserved across cell types, including cells of the central nervous 
system (CNS) (i.e., neurons, astrocytes, oligodendrocytes, microglia etc.) (Potolicchio et al., 2005; Fauré et al., 2006; Krämer-Albers et al., 2007; Goetzl et al., 2018b). Renewed interest in this class of extracellular vesicles, coupled with technological advances, has resulted in a variety of biochemical techniques to facilitate exosome analysis, including highsensitivity commercially available assays at a relatively low cost (Patel et al., 2019). Depending on the inherent properties of the sample (e.g., in vitro supernatant vs. clinical plasma/serum), processing generally involves isolation (e.g., ultracentrifugation, size exclusion chromatography, immunoaffinity, polymer precipitation etc.) and characterization (e.g., nanoparticle tracking, resistive pulse sensing, atomic force microscopy etc.) followed by biological interpretation of exosomal quantity and contents utilizing complementary biochemical techniques (e.g., high-throughput sequencing, proteomic arrays etc.) (Gurunathan et al., 2019). Given that differing cell types incorporate varying molecular components during endosomal sorting and exosome release, investigators can utilize this heterogeneity as molecular signatures to determine their cellular origin. Thus, exosomes released by neurons, astrocytes, oligodendrocytes, microglia, endothelial cells and pericytes can be differentiated according to antibody-based purification utilizing L1CAM (L1 cell adhesion molecule), GLAST (Glutamate aspartate transporter), PLP1 (Proteolipid protein 1), TMEM119 (Transmembrane protein 119), CD31 (cluster of differentiation 31) and PDGFR $\beta$ (platelet-derived growth factor receptor beta), respectively (Frühbeis et al., 2020; Kumar et al., 2020). The capacity to identify a given exosome's parent cell is particularly valuable given that peripheral exosomes can penetrate the blood-brain-barrier (BBB), while brain derived exosomes can be readily detected in systemic samples (AlvarezErviti et al., 2011; Banks et al., 2020; Kumar et al., 2021). It should be noted that a recent investigation suggested L1CAM may not be an appropriate marker to identify neuronal specific exosomes (Norman et al., 2021); however, the interpretation of such data as well as the reliability of these findings remain contested, including contrary evidence of L1CAM positive vesicles enriched for neuronal proteins (e.g., BDNF, neuronal enolase) (Mustapic et al., 2017; Suire et al., 2017).

Attempts have been made to categorize exosomes according to their net advantages or disadvantages for CNS homeostasis, yet such a dichotomous distinction may be misleading. For instance, accumulating evidence illustrates exosomes facilitate symbiotic dynamism between neurons and oligodendrocytes, whereby activity dependent synaptic transmission triggers exosomal secretion from oligodendrocytes that contain essential myelin components (e.g., myelin basic protein [MBP], myelin oligodendrocyte glycoprotein [MOG] etc.); subsequently, internalization of these exosomes amongst proximal neurons enhances cellular viability (Domingues et al., 2020). Conversely, data suggest exosomes can serve as pathological conduits, capable of spreading aggregate-prone polypeptides between cells in a prion-like manner, including $\mathrm{A} \beta$ oligomers and pTau (Sardar Sinha et al., 2018; Polanco et al., 2021). However, exosome biology is itself an evolutionary conserved process intertwined with a myriad of other fundamental cellular mechanisms, ranging from gene expression to lysosomal autophagy (Kalluri and LeBleu, 2020). Therefore, these extracellular vesicles could presumably represent causal pathogenic processes leading to cognitive decline, compensatory responses to confer neuroprotection or a common outcome from upstream cellular mechanisms (i.e., epiphenomenon). As exosomes likely serve varying functions under differing physiological conditions, the following sections defer from categorizing exosomes according to their net advantages or disadvantages for CNS homeostasis and instead highlight recent advances in our understanding for the role of exosomes in age-related cognitive decline.

\section{INSIGHTS FOR NEUROBIOLOGICAL MECHANISMS OF COGNITIVE DECLINE}

\section{MicroRNAs}

A large quantity of exosome research has focused on their capacity to incorporate and transport microRNAs (miRNAs). These short (18-25 base pairs in length; 22 avg.) noncoding RNAs function as post-transcriptional regulators of gene expression by binding to complementary pairing sites on mRNA (e.g., 3' UTR, 5' UTR, coding sequences etc.) across various locations within a cell, including the nucleus, cytoplasm and subcellular compartments, such as stress granules (O'Brien et al., 2018). Such binding subsequently influences expression of the targeted mRNAs, most notably by triggering their degradation and silencing the expression of transcripts which would otherwise be translated (Huntzinger and Izaurralde, 2011; Ipsaro and Joshua-Tor, 2015). Through these mechanisms, miRNAs maintain the capacity to influence a plethora of downstream processes that are dependent on gene expression, ranging from energy utilization to cellular growth. For example, miR-193b binds to the $3^{\prime}$ UTR of Amyloid Precursor Protein (APP) mRNA and represses its ensuing protein expression; interestingly, this miRNA also maintains significantly lower exosomal concentrations among AD patients, suggesting its low levels may exacerbate the generation of A $\beta$ (Liu et al., 2014; Yang et al., 2018). Although additional studies are required to fully elucidate the functional implications of miRNAs, their ubiquitous expression across varying physiological conditions coupled with their incorporation into exosomes has made them an attractive target for examining the underlying mechanisms of age-related cognitive decline.

Several studies have characterized systemic exosomal miRNAs among elderly individuals to identify potential downstream biological pathways that might facilitate late life cognitive dysfunction. Utilizing plasma-derived samples enriched with exosomes from healthy aged participants, one recent study analyzed miRNAs via multiplex sequencing and correlated their levels with performance on the Montreal Cognitive Assessment (MoCA). While a large set of miRNAs showed significant positive correlations with age, another set maintained significant negative correlations with cognitive performance, including those miRNAs selectively expressed in the brain. In turn, functional annotation of miRNAs associated with poor performance revealed several biological pathways, including 
neurotrophin signaling, whose miRNA-mediated regulation may be important mediators of cognitive decline (Rani et al., 2017). Furthermore, machine learning approaches indicated expression levels of such miRNAs could predict several other cognitive outcomes, including fluid, crystallized and overall cognition (Gullett et al., 2020). Reanalysis of the same data set using weighted gene co-expression network analyses (WGCNA) coupled with functional enrichment revealed modules of miRNAs whose regulation of cancer-related signaling pathways may also account for MoCA performance among elderly participants (Ye et al., 2020). Such results complement another study which compared exosome enriched CSF samples from cognitively intact elderly individuals to those diagnosed with AD. Here, AD individuals exhibited elevated exosome concentrations of miRNAs previously implicated in cognitive decline (i.e., miR-9-5p and miR-598). Given that complementary in silico analysis linked these miRNAs to stress response and neurotrophic signaling pathways, findings suggested miRNA mediated regulation of these biological processes may increase risk for cognitive decline (Riancho et al., 2017). Interestingly, exosomal miRNA regulation of such specific pathways (i.e., neurotrophic signaling, cancer-related signaling and stress response) has been reported in other investigations, suggesting these processes might constitute common biological mechanisms that are associated with late life cognitive dysfunction (Gui et al., 2015; McKeever et al., 2018; Gámez-Valero et al., 2019; Dong et al., 2021).

To gain more reliable insights into the neurobiological mechanisms of cognitive decline, additional investigations have interrogated the role of miRNAs from brain derived exosomes. After isolating neural exosomes from $\mathrm{AD}$ plasma samples, researchers recently identified a set of significantly upregulated (i.e., miR-23a-3p, miR-223-3p, and miR-190a-5p) and downregulated (i.e., miR-100-3p) miRNAs which were predicted to regulate several homeostasis pathways in the CNS, including steroid biosynthesis and mTOR signaling (Serpente et al., 2020). In another recent investigation, neural exosomes isolated from plasma samples revealed two miRNAs (i.e., miR132 and miR-212) whose degree of downregulation was capable of distinguishing $\mathrm{AD}$ stages (i.e., $\mathrm{AD}$ vs. MCI vs. Control). Although investigators here inferred the biological relevance of these miRNAs, potential regulation of specific downstream processes was not examined (Cha et al., 2019).

Preclinical investigations have also characterized exosomal miRNAs to identify potential biological pathways that might facilitate cognitive decline. Utilizing exosomes harvested from hippocampal stem cell cultures, a group of researchers identified a set of miRNAs (i.e., miR-17, miR-322, and miR-485) whose in vivo delivery via exosomes was capable of ameliorating memory deficits in rodents (i.e., Novel Object Recognition) otherwise induced by intracerebral application of $\mathrm{A} \beta$ oligomers; furthermore, researchers inferred these benefits may be attributed to the increased synaptic phosphorylation of calmodulindependent kinase II (Micci et al., 2019). Similar results have been noted among in vitro studies, whereby the transfer of miRNAs via exosomes from healthy stem cells can induce significantly improved viability in recipient neural cells by modulating alternative intracellular signaling cascades (e.g., PTEN/PI3K/Akt pathway) (Wei et al., 2020; Cong et al., 2021).

To expand our understanding for the role of exosomal miRNAs in mediating the underlying mechanisms of cognitive decline, several lines of inquiry require elucidation, some of which are addressed below. For one, we currently lack a comprehensive understanding of the mechanisms within recipient cells that are modulated by exosomal miRNAs. Previous evidence suggests miRNAs released by exosomes remain functional in their recipient cells, capable of directly downregulating the expression of target transcripts, similar to endogenous effects in parent cells (Umezu et al., 2013; Zhou et al., 2014). Interestingly, exosomal miRNA can also influence mechanisms in recipient cells other than gene expression, such as serving as ligands for Toll-Like Receptors in intracellular endosomes and triggering their activation (Fabbri et al., 2012). Given that prior studies have disproportionately relied on cellular models of peripheral origin, it would be beneficial to discern the precise cellular mechanisms altered by exosomal miRNAs as well as assess if such effects differ depending on CNS cell type. Related to this gap in knowledge, observations indicate the ratio of a given miRNA copy to the number of exosomes is substantially below one, with an average of one per 121 exosomes (Chevillet et al., 2014). This suggests additional investigations should more accurately quantify the association between exosomal miRNA content and ensuing functional alterations in CNS cells, such as effects of a single miRNA from one exosome and synergistic effects of multiple miRNAs from different exosomes. Along with miRNAs, accumulating data indicate exosomes can translocate other types of non-coding RNAs, including long non-coding RNAs (lncRNAs), ribosomal RNAs and circular RNAs (Huang et al., 2013; Li et al., 2015). By examining how these other exosomal non-coding RNAs interact with miRNAs to exert variation in CNS processes, investigators will likely gain a greater understanding of the neurobiological mechanisms contributing to cognitive decline in late life.

\section{Neuroinflammation}

A mild state of chronic neuroinflammation in the absence of overt infection referred to as sterile inflammation, or inflammaging, is a common feature of normal aging. Higher levels of neuroinflammation are a risk factor for age-related cognitive decline and the accumulation of neuropathological hallmarks (Wyss-Coray and Rogers, 2012; Franceschi and Campisi, 2014; Ransohoff, 2016). Neuroinflammation can be quantified through a diverse set of variables, including levels of inflammatory messengers (e.g., cytokine, chemokines, prostaglandins) and phenotypic characteristics of CNS cells which mediate immune processes (e.g., microglia, astrocytes) (Glass et al., 2010). In the event of infection or injury, optimal neuroinflammation can promote neuroprotective effects, yet its dysregulation from a variety of factors in aging (e.g., increased iron load, accumulation of lipid droplets, oxidative stress etc.) can result in an aberrant, pro-inflammatory state (Wong, 2013; Ransohoff, 2016; Rea et al., 2018). In turn, this can induce deleterious consequences for homeostatic processes in CNS cells and contribute to an increased risk for cognitive decline and neurodegeneration. Investigations 
utilizing a variety of techniques (e.g., genomic, neuroimaging etc.) across experimental designs (i.e., clinical and preclinical) support the association between increased neuroinflammation and late life cognitive dysfunction (He et al., 2007; Cribbs et al., 2012; Kreisl et al., 2013; Elmore et al., 2018; Duggan and Parikh, 2021).

The modulation of neuroinflammatory processes by exosomes has been increasingly scrutinized in the context of several conditions, including neurodegenerative diseases and traumatic brain injury (Gupta and Pulliam, 2014; Thomi et al., 2019; Kumar et al., 2021). A recent interrogation elegantly addressed this mechanism by isolating astrocyte and neuronal exosomes from plasma samples of $\mathrm{AD}$ patients and examining their subsequent in vitro effects on several neuronal populations, including rat cortical neurons as well as human iPSC-derived neurons. Compared to age-matched and cognitively sound participants, brain derived exosomes from $\mathrm{AD}$ individuals triggered a robust activation of the complement cascade (i.e., an immune response pathway for host defense against infections), which ultimately resulted in the disruption of plasma membrane integrity as well as elevated neurotoxicity (Nogueras-Ortiz et al., 2020). Such findings were consistent with results from another study, which illustrated increased concentrations of multiple complement cascade proteins in astrocyte derived exosomes from $\mathrm{AD}$ individuals, including C1q and C4b (Goetzl et al., 2018b).

The role of exosomes in mediating neuroinflammatory mechanisms underlying cognitive decline has disproportionally relied on preclinical models, particularly transgenic animals. In APP/PS1 double transgenic mice, recent investigations have shown the administration of exosomes from healthy, bone marrow derived mesenchymal stem cells can normalize neuroinflammation across the cortex and hippocampus [i.e., decrease pro-inflammatory cytokines (TNF- $\alpha$, IL- $1 \beta$, and IL-6); increase anti-inflammatory cytokines (IL-10, IL-4, and IL-13)]; in turn, this is associated with the mitigation of pathological peptides (i.e., $A \beta$ concentrations, plaque deposition) and the preservation memory capacities (i.e., Morris Water Maze). Interestingly, such beneficial effects on cognition and neuroinflammation were comparable when exosomes were specifically targeted to the brain or administered systemically, highlighting the capacity of these EVs to exert their effects across the BBB (Cui et al., 2018, 2019). Follow-up studies have expounded on these findings by illustrating the exosomal moderation of neuroinflammatory processes and ensuing benefits to cognitive performance may be attributed to effects on microglia specifically (i.e., the resident macrophage of the CNS) (Ding et al., 2018; Li et al., 2020; Zhang et al., 2021).

To enhance our understanding of exosomal-mediated neuroinflammation and associated risk for cognitive decline, several lines of evidence require further interrogation. Most prominently, further studies are needed to characterize the contents of exosomes which are responsible for alterations in CNS inflammation. Along with pathogens (e.g., bacteria, viruses), a variety of molecules can induce immune responses in the brain, including reactive oxygen species (ROS), purine metabolites (e.g., urate crystals), calcium-binding proteins and lipotoxic ceramides (Ransohoff and Perry, 2009; Chen and Nunez, 2010;
Goldberg and Dixit, 2015). In addition to screening for exosomal contents, investigations should distinguish how these molecules delivered to the intracellular environment differentially trigger inflammatory responses compared to their previously characterized effects, many of which have been assessed at the extracellular surface (e.g., cytokines binding to receptors). Evidence also indicates inflammation emanating from the periphery can increase the risk for late life cognitive impairments, either by lowering the threshold for activation in the CNS or exacerbating ongoing neuroinflammation (Holmes et al., 2009; Cunningham, 2013; Widmann and Heneka, 2014; Barter et al., 2021). Indeed, data suggest exosomes can be integral to this process: epithelial cells at the choroid plexus increase production of exosomes containing proinflammatory miRNAs in response to increased systemic inflammation (Balusu et al., 2016). Given that exosomes themselves can also exert their effects across the $\mathrm{BBB}$, further studies should assess how peripheral inflammatory states facilitate variation in neuroinflammation via exosomes and increase the likelihood for cognitive deterioration in elderly individuals.

\section{Aggregate-Prone Proteins}

Evidence indicating the association between aggregate-prone proteins (i.e., $\mathrm{A} \beta, \mathrm{p}$ Tau) and age-related cognitive decline is abundant, with increasing data suggesting their spread between CNS cells can be facilitated through exosomes (Wang et al., 2017; Sardar Sinha et al., 2018). It should be reiterated that cognitive decline can occur independent from measures of neuropathology, while behavioral symptomology is often accompanied by a mixture of neuropathological hallmarks (White et al., 2016; Aiello Bowles et al., 2019). Although debate persists regarding whether these polypeptides are pathogenic, neuroprotective or epiphenomena of upstream mechanisms, it is thought their abnormal abundance and ensuing aggregation (i.e., due to increased production and/or decreased degradation) can perturb homeostatic processes in CNS cells, facilitate neuronal malfunctioning and contribute to the manifestation of behavioral symptomology (Espay et al., 2019; Mathieu et al., 2020). Rather than discuss the causal relevance of these proteins, the subsequent section instead focuses on evidence of their transport within exosomes and implications for the biological underpinnings of cognitive decline.

Several investigations have leveraged aggregate-prone proteins in exosomes to predict individual variation in cognitive decline as well as their capacity to mediate its underlying neurobiological mechanisms. In one study with a 3 year follow up period, levels of $A \beta_{1-42}$, pTau-181 and pTau-S396 in neuronal exosomes isolated from blood samples could differentiate AD patients from controls, as well as those patients with MCI who remained cognitively stable from those who illustrated progressively declining MMSE scores. Furthermore, intracerebral injection of such exosomes into healthy adult mice induced a significant accumulation of pTau in CA1 pyramidal neurons, compared to those exosomes from stable MCI participants (Winston et al., 2016). For $A \beta_{1-42}$ specifically, data indicate its levels in neuronal exosomes offers similar capacity to predict deterioration 
in cognitive performance; among participants diagnosed with MCI according to a battery of tests (e.g., MMSE, MoCA, ADAS-cog, AVLT), individuals who illustrated higher exosomal $\mathrm{A} \beta_{1-42}$ levels maintain an 11.1- and 8.5-fold increased risk for significant cognitive deterioration at 2 and 3 year followup assessments, respectively, compared to MCI participants who remained cognitively stable (Zhao et al., 2020). Similar capacity to predict longitudinal cognitive performance has been noted for neuronal exosome concentrations of total Tau and pTau (Nam et al., 2020). Furthermore, in vitro and in vivo investigations have demonstrated $\mathrm{A} \beta$ as well as Tau in brain derived exosomes can readily compromise neuronal viability and induce cell death (Winston et al., 2019; Elsherbini et al., 2020a,b; Ruan et al., 2020). Together, these data suggest exosomal concentrations of aggregate-prone peptides can induce aberrant biological consequences in CNS cells (e.g., protein aggregation, apoptosis etc.) and may constitute an important mechanism leading to increased risk for cognitive impairments in aging.

Although exosomal transfer of aggregate-prone peptides may be an important mechanism underlying cognitive decline, several related processes require further investigation. Notably, data have yet to elucidate how exosomal propagation of other aggregateprone peptides (i.e., TDP-43, $\alpha$-synuclein) may synergistically compromise CNS homeostasis (Iguchi et al., 2016; Ngolab et al., 2017; Niu et al., 2020; Zhang et al., 2020). Such a gap in knowledge is particularly relevant provided that age-related cognitive deficits are often associated with the accumulation of multiple species of aggregate-prone peptides (Schneider et al., 2007; Rahimi and Kovacs, 2014; James et al., 2016; White et al., 2016). Additional experiments should also examine how the uptake of pathologically relevant proteins by microglia differentially contributes to the clearance of such peptides, as well as their potential spread to proximal cells via exosomes. As microglia inherently play a role in $A \beta /$ Tau degradation via phagocytosis, and can facilitate the spread of aggregate-prone peptides via the secretion of $A \beta /$ Tau-containing EVs, it remains unknown to what degree microglia contribute both to the degradation of such proteins as well as their propagation via exosomes (Joshi et al., 2014; Asai et al., 2015; Gouwens et al., 2018). In addition, studies should determine if the transfer of transcripts encoding for aggregate-prone peptides (e.g., $A P P, M A P T$ ) via exosomes is capable of increasing translation of these proteins in recipient cells; such exploitation of host cell gene expression machinery could facilitate the accumulation of protein aggregates in otherwise healthy CNS cells (Gui et al., 2015; Khan et al., 2016; O'Brien et al., 2020). Another unique aspect that requires elucidation is the attachment of aggregate-prone proteins to the surface of exosomes, rather than their inclusion into the exosomal milieu. For instance, evidence suggests $A \beta$ as well as its degradation enzymes can be attached to the membrane surface of exosomes (Bulloj et al., 2010; Yuyama et al., 2014; Lim et al., 2019). Further investigations are encouraged to determine how aggregate-prone proteins, attached to the surface of exosomes, confer effects on the extracellular environment (e.g., extra-cellular matrix dysregulation, plaque deposition etc.) and whether these effects increase the likelihood for cognitive deterioration in aging.

\section{USING EXOSOMES TO IMPROVE OUTCOMES IN COGNITVE DECLINE}

\section{Exosomes as Biomarkers to Predict Dementia}

Predicting individual cognitive trajectories in aging can be important for diagnostic purposes, and the adoption of exosomes as biomarkers may prove particularly useful in this respect. Clinical assessment alone can fail to discriminate those individuals who maintain cognitive resilience from those who develop MCI, as well as those MCI patients who go on to develop dementia (Frölich et al., 2017; Sabbagh et al., 2017; Albert et al., 2018). Although PET neuroimaging and CSF assessments via lumbar puncture can augment diagnostic sensitivity and specificity of tests to detect plaques and tangles, such approaches can be invasive, lengthy and costs are not routinely covered by insurance. Furthermore, early detection of vulnerable individuals may help improve patient outcomes and offer an opportunity for earlier interventions. Indeed, the only FDA approved treatments for dementia (i.e., cholinesterase inhibitors, NMDA antagonist, $\mathrm{A} \beta$ antibodies) are specified for persons already exhibiting symptoms; however, the underlying neurobiology of cognitive decline is hypothesized to begin years or decades before the onset of behavioral impairments (Long and Holtzman, 2019). Therefore, using exosomes as biomarkers to enhance detection of susceptible individuals may facilitate intervention by health care providers (e.g., enrolling in clinical trials, implementing riskreduction strategies) and ultimately improve prognosis (Ngandu et al., 2015; Seifan and Isaacson, 2015).

Numerous studies have used miRNAs isolated from bloodderived exosomes as biomarkers to classify individuals who are exhibiting late life cognitive dysfunction. Table 1 summarizes clinical investigations that have developed algorithms based on machine learning and other statistical approaches to predict diagnostic status using miRNA from exosomes. Altered expression of larger (i.e., 7-16) as well as more limited (i.e., 1-3) panels of specific miRNAs are capable of accurately distinguishing between clinical cases with $\mathrm{AD}$ dementia and healthy, aged-matched controls (Liu et al., 2014; Cheng et al., 2015; Lugli et al., 2015; Wei et al., 2018; Dong et al., 2021). In addition, miRNAs from blood-derived exosomes have also been used to differentiate dementia phenotypes (i.e., AD dementia, Lewy Body dementia, Vascular dementia etc.) (Yang et al., 2018; Gámez-Valero et al., 2019; Barbagallo et al., 2020). Although several studies have directly associated exosomal miRNAs with acute cognitive performance (e.g., MoCA, MMSE, CDR), further evidence is needed to extrapolate such associations with performance over time (Rani et al., 2017; Wei et al., 2018; Gullett et al., 2020).

Compared to blood samples, available evidence suggests measures of exosomal miRNAs obtained from CSF samples offer similar accuracies in distinguishing individuals with agerelated cognitive impairment (Liu et al., 2014; Gui et al., 2015; McKeever et al., 2018). However, results from several studies highlight important considerations for miRNA biomarker assessment in CSF exosomes. For example, while lower levels 
TABLE 1 | Clinical studies using exosome-derived microRNAs to predict dementia.

\begin{tabular}{|c|c|c|c|c|c|}
\hline $\begin{array}{l}\text { Source of } \\
\text { exosome }\end{array}$ & microRNA (miR) & $\begin{array}{l}\text { Prediction } \\
\text { model/diagnostic } \\
\text { evaluation }\end{array}$ & Biomarker accuracy & $\begin{array}{l}\text { Clinical } \\
\text { classification }\end{array}$ & References \\
\hline Serum & $\begin{array}{l}\text { Upregulated in AD: miR18b-5p, miR-20a-5p, miR30e-5p, } \\
\text { miR-582-5p, miR-106a-5p, miR-361-5p, miR-143-3p, miR-424-5p, } \\
\text { miR-93-5p, miR-106b-5p, miR-101-3p, miR-335-5p, miR-15a-5p } \\
\text { Downregulated in AD: miR-1306-5p, miR342-3p, miR-15b-3p }\end{array}$ & Random decision forest & $\begin{array}{l}\text { Combined panel of } 16 \text { miRs: sensitivity } \\
87 \% \text {;specificity } 77 \%\end{array}$ & HC vs. AD & Cheng et al., 2015 \\
\hline Serum & $\begin{array}{l}\text { Upregulated in AD: miR-22-3p, miR-378a-3p } \\
\text { Downregulated in AD: miR-30b-5p }\end{array}$ & $\begin{array}{l}\text { Logistic regression, } \mathrm{ROC} \\
\text { curve analysis }\end{array}$ & $\begin{array}{l}\text { Combined panel of } 3 \text { miRs: } \\
\text { AUC } 0.88\end{array}$ & HC vs. AD & Dong et al., 2021 \\
\hline Serum & Downregulated in AD: miR-223 & $\begin{array}{l}\text { Spearman correlation, } \mathrm{ROC} \\
\text { curve analysis }\end{array}$ & $\begin{array}{l}\text { MMSE scores }(r=0.37) \text {; CDR scores } \\
(r=0.46) ; \text { AUC } 0.88\end{array}$ & HC vs. AD & Wei et al., 2018 \\
\hline Serum & $\begin{array}{l}\text { Upregulated in AD: miR-135a, miR-384 } \\
\text { Downregulated in AD: miR-193b }\end{array}$ & ROC curve analysis & 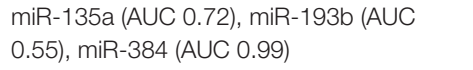 & AD vs. VD & Yang et al., 2018 \\
\hline Serum & Upregulated in AD: miR-22, miR-23a, miR-29a, miR-34b, miR-130b & $\begin{array}{l}\text { Logistic regression, } \mathrm{ROC} \\
\text { analysis }\end{array}$ & 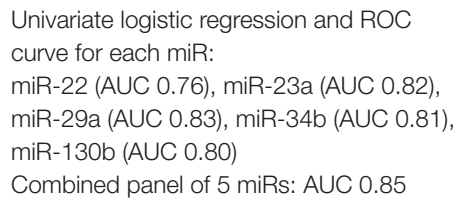 & AD vs. VD & Barbagallo et al., 2020 \\
\hline Serum \& Plasma & Downregulated in AD: miR-193b & Mann-Whitney U Test & $\operatorname{miR}-193 b(p<0.05)$ & $\begin{array}{l}\mathrm{HC} \text { vs. } \mathrm{AD} \\
\mathrm{HC} \text { vs. } \mathrm{MCl} \\
\mathrm{MCl} \text { vs. } \mathrm{AD}\end{array}$ & Liu et al., 2014 \\
\hline Plasma & $\begin{array}{l}\text { Downregulated in AD: miR-342-3p, miR-141-3p, miR-342-5p, } \\
\text { miR-23b-3p, miR-24-3p, miR-125b-5p, miR-152-3p }\end{array}$ & $\begin{array}{l}\mathrm{J} 48 \text { decision tree, SVM, } \\
\text { adaboostM1, ROC curve } \\
\text { analysis }\end{array}$ & $\begin{array}{l}\text { Combined panel of } 7 \text { miRs: } \\
\text { precision (J48 decision tree 0.78, SVM } \\
0.82 \text {, AdaboostM1 0.89); } \\
\text { AUC (J48 decision tree 0.75, SVM 0.83, } \\
\text { AdaboostM1 0.92) }\end{array}$ & HC vs. AD & Lugli et al., 2015 \\
\hline Plasma & Downregulated in AD: miR-451a, miR-21-5p & ROC curve analysis & 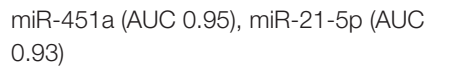 & AD vs. DLB & $\begin{array}{l}\text { Gámez-Valero et al., } \\
2019\end{array}$ \\
\hline Plasma & $\begin{array}{l}\text { Upregulated miRs correlated with lower MoCA scores: } \\
\text { miR-342-3p, miR-125b-5p, miR-10a-5p, miR-140-3p, miR-451a, } \\
\text { miR-99a-5p, miR-23b-3p, miR-10b-5p, miR-125a-5p, miR-186-5p, } \\
\text { miR-378a-3p, miR-26b-5p, miR-30c-5p }\end{array}$ & Multiple regression & $\begin{array}{l}\text { Coefficients (age }-0.063 \text { to }-0.074 \\
\text { miR }-1.00 \text { to }-1.74 \text { ); } R^{2} 0.12 \text { to } 0.15 \\
p<0.05 \text { to } 0.01\end{array}$ & $\begin{array}{l}\text { Older adults } \\
\text { (60-89 years) }\end{array}$ & Rani et al., 2017 \\
\hline CSF & $\begin{array}{l}\text { Downregulated in AD: miR-29c, miR-136-3p, miR-16-2, miR-331-5p } \\
\text { Upregulated in AD: miR-132-5p, miR-485-5p }\end{array}$ & ANOVA & $\begin{array}{l}\text { Fold Change } \\
\text { miR-29c (-0.47), miR-136-3p (-0.12), } \\
\text { miR-16-2 (-0.83), miR-331-5p (-0.61), } \\
\text { miR-132-5p (0.12), miR-485-5p (1.39) }\end{array}$ & HC vs. AD & Gui et al., 2015 \\
\hline CSF & $\begin{array}{l}\text { Downregulated in AD: miR-451a, miR-605-5p } \\
\text { Upregulated in AD: miR-125b-5p }\end{array}$ & ROC curve analyses & $\begin{array}{l}\text { AUC (EOAD/LOAD) } \\
\text { miR-451a }(0.95 / 0.85) \\
\text { miR-605-5p }(0.71 / 0.77) \\
\text { miR-125b-5p }(0.72 / 0.79)\end{array}$ & $\begin{array}{l}\text { HC vs. LOAD } \\
\text { HC vs. YOAD }\end{array}$ & McKeever et al., 2018 \\
\hline CSF & Downregulated in AD: miR-193b & Spearman correlation & $\operatorname{CSF} A \beta$ load $(r=-0.44, p<0.05)$ & $A D$ & Liu et al., 2014 \\
\hline
\end{tabular}


of miR-193b in exosomes derived from serum, plasma or CSF can differentiate $\mathrm{AD}$ patients from controls, levels of miR-193b in CSF exosomes can discriminate AD patients more accurately than levels from serum exosomes (i.e., $71.4 \%$ vs. 58.8\%) (Liu et al., 2014). In addition, when miRNA measurements are derived from CSF, it should be noted that differential concentrations of some miRNAs in $\mathrm{AD}$ subjects may illustrate opposite patterns of expression depending on whether such miRNAs are encapsulated in exosomes or soluble in CSF (Riancho et al., 2017). Regarding non-miRNA biomarkers, measurements of $\mathrm{AD}$-specific biomarkers (i.e., $\mathrm{A} \beta$, pTau) maintain robust correlations across blood and CSF samples, thereby offering similar capacities to discriminate participants with age-related cognitive impairment (Jia et al., 2019; Janelidze et al., 2020).

Although there is no consensus on which individual miRNAs or groups of miRNAs from exosomes best predict cognitive impairment, some consistent evidence has emerged. For example, levels of miR-342-3p in plasma exosomes were significantly lower in $\mathrm{AD}$ participants compared to controls and correlated with poor cognitive performance (i.e., MoCA) among elderly, cognitively unimpaired individuals in a separate study (Lugli et al., 2015; Rani et al., 2017). Similarly, data across multiple cohorts indicate serum exosomes from $\mathrm{AD}$ individuals maintain lower levels of miR-193b (Liu et al., 2014; Yang et al., 2018). However, some inconsistent results have been reported; for instance, results suggest CSF exosomes from $\mathrm{AD}$ patients exhibit increased levels of miR-125b-5p, yet data from another study indicate its levels in plasma exosomes are associated with poor cognitive performance (Rani et al., 2017; McKeever et al., 2018). As there appears to be minimal concordance across studies, the application of exosomal miRNAs as reliable diagnostic indicators may currently be limited to within particular individuals (Dong et al., 2020).

In addition to cross-sectional investigations, several studies have used exosomes as biomarkers to predict longitudinal variation in cognitive decline. Using neurally derived exosomal concentrations of aggregate-prone peptides, researchers can predict individuals who progress from $\mathrm{MCI}$ to $\mathrm{AD}$-dementia within 36 months (i.e., via MMSE scores), as well as cognitively sound individuals who develop dementia up to 10 years later (i.e., via CDR scores) (Fiandaca et al., 2015; Winston et al., 2016). Increased longitudinal accuracy can be achieved by combining such exosomal concentrations of aggregate-prone peptides with other performance measures (e.g., olfactory function) or other exosomal cargo (e.g., insulin receptor substrates; IRS) (Kapogiannis et al., 2015; Zhao et al., 2020). For instance, by coalescing measures of pTau and phosphorylated IRS-1 from exosome-enriched plasma samples, researchers can predict (i.e., $>80 \%$ accuracy) elderly individuals who remain cognitively resilient from those who eventually display cognitive decline (i.e., mean follow up $3.5 \pm 2.31$ years) (Kapogiannis et al., 2019). It should be noted these aggregate-prone peptides in exosomes can also distinguish degrees of cognitive impairment in cross-sectional studies (i.e., healthy control vs. MCI vs. AD) (Jia et al., 2019; Nam et al., 2020; Perrotte et al., 2020). The most consistent results from neuronal-specific exosomes across different investigators and cohorts suggests a positive association between $\mathrm{AD}$-specific biomarkers (i.e., $\mathrm{A} \beta$, pTau) with crosssectional and longitudinal risk of cognitive impairment (Fiandaca et al., 2015; Winston et al., 2016; Jia et al., 2019; Nam et al., 2020; Zhao et al., 2020).

To enhance the utilization of exosomes as reliable and valid biomarkers, several important limitations should be considered. When examining their associations with cognitive decline, researchers should take steps to differentiate the tissue-specific (i.e., systemic vs. brain) as well as the cell-specific origin of exosomes. Indeed, data indicate exosomes from the CNS contain significantly different molecular contents depending on an individual's cognitive capacities (i.e., healthy controls vs. dementia) as well as their cellular origin (i.e., neurons vs. astrocytes), while such differences in content can subsequently induce distinct functional consequences for recipient cells (Goetzl et al., 2016b; Iguchi et al., 2016; Nogueras-Ortiz et al., 2020). Investigations should also consider steps to improve the diagnostic accuracy of exosomes for early stages of cognitive decline, given that current approaches differentiate healthy individuals from dementia cases more accurately than from MCI cases (Xing et al., 2021).

Despite limitations, the implementation of exosomes as biomarkers for age-related cognitive decline offers several advantages. As mentioned previously, exosomal sampling is more cost effective and less invasive than currently available biomarkers (i.e., CSF, PET). Furthermore, exosomes derived from the CSF and blood offer similar accuracy for identifying individuals exhibiting cognitive decline, while neuroimaging and blood derived exosomes exhibit similar specificity for distinguishing dementia cases from healthy controls (Gui et al., 2015; Jia et al., 2019; Lim et al., 2019). Meanwhile, exosomes can be sampled from several biological fluids (e.g., blood, saliva, urine, breast milk) (Pisitkun et al., 2004; Gallo et al., 2012; Mirza et al., 2019). Indeed, recent reports indicate neuronal exosomes can be isolated from saliva, while urinary exosomes can classify dementia patients from healthy controls (Rani et al., 2019; Sun et al., 2019). Additionally, the diversity of exosomal content presents investigators with the unique opportunity to improve diagnostic capacity; compared to approaches which assess a single molecular target (e.g., proteins), exosomes can enable researchers to leverage information simultaneously from a variety of molecular targets (e.g., proteins, lipids, RNA, DNA) (Thakur et al., 2014; Dinkins et al., 2017; Asada et al., 2019; TeruelMontoya et al., 2019). However, comparisons across studies should be restricted to samples of the same biological fluid, given that preparations from different biological fluids incur differing degrees of contamination during preparation (Grigor'eva et al., 2017).

\section{Engineered Exosomes as a Cargo Delivery Vehicle for Cognition Therapeutics}

Along with their diagnostic applications, exosomes can potentially serve as efficient delivery vehicles for the treatment of age-related cognitive dysfunction. Compared to traditional 
drug delivery, exosomes offer a number of benefits including their capacity to translocate functional biomolecules, their stability in blood, and immune tolerance (Pêche et al., 2006; Sun et al., 2013; Song et al., 2016). Naturally occurring exosomes derived from a variety of sources have been investigated for therapeutic applications, including those from different mammalian cells (e.g., mesenchymal stem cells, macrophages, tumor cells), plant cells, and biological fluids (e.g., plasma, serum, and milk) (Luan et al., 2017; Alfieri et al., 2021; Kučuk et al., 2021; Perut et al., 2021). Isolated exosomes can be exogenously loaded with therapeutic cargo for targeted delivery, ranging from RNAs (siRNA, miRNA, lncRNA) and proteins to synthetic chemicals and drugs. Numerous methodological approaches have been developed for modifying exosome contents for specific clinical applications, including passive (e.g., incubation) and active processes (e.g., sonication, extrusion, electroporation, chemical transfection) (Luan et al., 2017; Fu et al., 2020). Exosomes can also be modified to target a precise cell type within a given tissue by click chemistry methods that attach molecules of interest to the luminal surface via covalent bonds, or by manipulating exosome-producing parent cells in vitro (i.e., gene transfection, drug treatment) (Ohno et al., 2013; Smyth et al., 2014; Nakase and Futaki, 2015; Qi et al., 2016; Conlan et al., 2017). For instance, to generate exosomes that specifically target glioma cells, researchers have attached a neuropilin-1 peptide to cargo-loaded exosomes utilizing copper-catalyzed cycloaddition reactions of sulfonyl azide (Jia et al., 2018). Researchers have also developed transfection strategies to facilitate exosomal delivery to neurons and glia, such as fusing the rabies viral glycoprotein with the gene encoding for exosome transmembrane protein lysosomeassociated membrane protein 2b (LAMP2B) (Alvarez-Erviti et al., 2011). Similar transfection strategies have enabled therapeutic delivery to glioma cells, whereby the fusion of a transferrin receptor peptide T7 with LAMP2B enabled the delivery of miRNA oligonucleotides against miR-21 (Kim et al., 2020).

Perhaps the greatest advantage offered by exosomes is their capacity to transverse the BBB due to their small size, endogenous biological properties, and low immunogenicity, which has otherwise been a major obstacle in treatment development for cognitive decline (Pardridge, 2020). This has enabled the systemic administration of exosomes to efficiently deliver genetic material (e.g., oligonucleotides, miRNAs) and therapeutic drugs to the brain, where they induce functional alterations in targeted CNS cell types (Alvarez-Erviti et al., 2011; Kim et al., 2020). Numerous animal studies have evaluated the potential use of exosomes as drug delivery mechanisms for age-related neurodegenerative disorders and neuroinflammatory conditions. Across several different mouse models, including those exposed to lipopolysaccharide (LPS)-induced CNS inflammation and experimental autoimmune encephalitis, the intranasal delivery and subsequent CNS uptake of exosomes loaded with anti-inflammatory compounds (i.e., curcumin or Stat3inhibitor) protected mice from the deleterious effects otherwise associated with aberrant neuroinflammation (e.g., increased proinflammatory cytokine expression, increased disease severity) (Zhuang et al., 2011). Similarly, in a mouse model of ischemic stroke, the incorporation of neuron specific fusion proteins on the exosomal surface along with the intravenous application of such exosomes was capable of delivering specific compounds (e.g., miRNAs, flavonoids) to the CNS, where they exerted neuroprotective effects and promoted neuronal viability (Yang et al., 2017; Guo et al., 2021). Furthermore, evidence suggests exosomes can ferry cargo across the BBB without exogenous modification of CNS-targeting peptides on their surface. For instance, due to their inherent brainhoming peptides, exosomes isolated from macrophages and administered intravenously can deliver brain-derived neurotrophic factor (BDNF) to the CNS (Yuan et al., 2017). Likewise, systemic administration of macrophage-derived exosomes loaded with glial cell-line derived neurotrophic factor (GDNF) reduced neuroinflammation and ameliorated degeneration of dopaminergic neurons in a mouse model of Parkinson's disease (PD) (Zhao et al., 2014). In another mouse model of PD, systemic administration of macrophage-derived exosomes delivered an antioxidant enzyme to dopaminergic neurons and resulted in significantly improved motor function (Haney et al., 2015). Beneficial effects have also been reported in transgenic $\mathrm{AD}$-mice following intraparietal injection of brain-specific exosomes containing quercetin; here, exosomal delivery across the BBB resulted in an attenuation of memory and spatial learning deficits, as well as the mitigation of neuropathological hallmarks (e.g., pTau, neurofibrillary tangles) (Qi et al., 2020).

Although engineered exosomes may eventually prove more effective, existing evidence from stem cell derived exosomes demonstrates that even un-modified exosomes hold promise for dementia treatment. In APP/PS1 mice across several research groups, the application of exosomes isolated from cultured stem cells (human umbilical, mouse bone barrow, mouse embryonic) can reliably improve performance on cognitive tasks (novel object recognition, Morris Water Maze) and inhibit biological processes associated with cognitive impairment, including the dysregulated expression of pro- and anti-inflammatory cytokines (IL1- $\beta$ and IL-10), the activation of CNS immune cells (astrocytes, microglia) and the deposition of $A \beta\left(A \beta_{1-40}, A \beta_{1-42}\right.$, plaques) (Cui et al., 2018, 2019; Ding et al., 2018; Wang et al., 2018; Li et al., 2020; Yang et al., 2020). Additional data has suggested such protective effects observed across multiple $\mathrm{AD}$ mouse models may be due to the natural inclusion of antioxidants (bioactive catalase) and $A \beta$ degrading enzymes (neprilysin, insulin degrading enzyme) in stem cell exosomes (de Godoy et al., 2018; Ding et al., 2018; Lee et al., 2018; Bodart-Santos et al., 2019; Elia et al., 2019; Micci et al., 2019; Apodaca et al., 2021). Together, these animal studies support the therapeutic potential of engineered exosomes as CNSspecific delivery vehicles to ameliorate cellular and cognitive dysfunction (Figure 1).

While the clinical development of therapeutic interventions faces a variety of hurdles, the consideration of exosomes as a novel delivery vehicle for future nanotherapeutics 


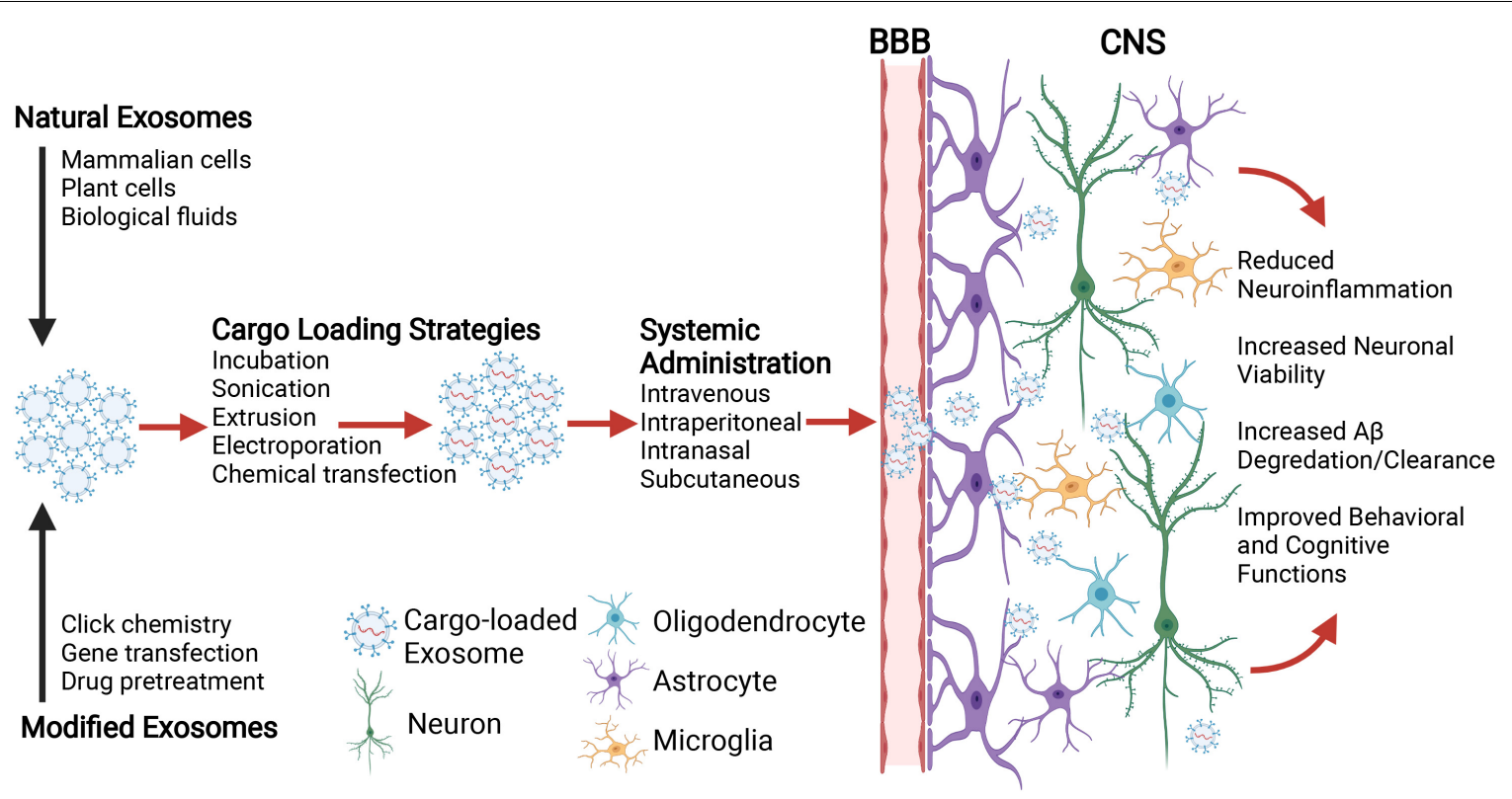

FIGURE 1 | Schematic illustration depicting the application of exosomes for central nervous system (CNS) delivery of therapeutic cargo to combat the neurobiological underpinnings of age-related cognitive decline. Natural exosomes or those modified for targeted delivery to specific brain cells (e.g., neurons, oligodendrocytes, astrocytes, and microglia) are loaded with therapeutic molecular cargo (e.g., nucleic acids, proteins, and drugs) using passive or active strategies. Exosomes are then administered systemically, where the route of administration depends upon multiple parameters including stability, biodistribution, dose, and therapeutic efficacy. With their inherent capacity to penetrate the blood brain barrier (BBB), exosomes ferry therapeutic cargos to the targeted brain cells and ameliorate aberrant neurobiological processes (e.g., neuroinflammation, neuronal cell death, A $\beta$ degradation/clearance etc.) that may otherwise contribute to age-related cognitive decline. Created with Biorender.

TABLE 2 | Clinical trials involving exosome-based therapeutic interventions for neurological disorders (ClinicalTrials.gov Database, 2022).

\begin{tabular}{|c|c|c|c|c|}
\hline Exosome Intervention & Route of administration & Therapeutic condition & Outcome measures & Clinical trial ID \\
\hline $\begin{array}{l}\text { Allogenic adipose MSC-derived } \\
\text { exosomes }\end{array}$ & Intranasal & $A D$ & $\begin{array}{l}\text { Adverse event, cognitive } \\
\text { function, quality of life, } A D \\
\text { biomarkers }\end{array}$ & NCT04388982 \\
\hline $\begin{array}{l}\text { Focused ultrasound delivery of } \\
\text { exosomes }\end{array}$ & Intravenous & $\begin{array}{l}\text { Refractory depression, } \\
\text { anxiety disorders, and } \\
\text { neurodegenerative } \\
\text { dementia }\end{array}$ & $\begin{array}{l}\text { Depressive and anxiety } \\
\text { symptoms, cognitive function }\end{array}$ & NCT04202770 \\
\hline $\begin{array}{l}\text { Allogenic MSC-derived exosomes } \\
\text { transfected with miR-124 }\end{array}$ & Stereotaxis/intraparenchymal & Cerebrovascular disorders & $\begin{array}{l}\text { Stroke recurrence, seizure, } \\
\text { hemorrhage, disability }\end{array}$ & NCT03384433 \\
\hline $\begin{array}{l}\text { Exosomes containing neonatal stem } \\
\text { cell products }\end{array}$ & $\begin{array}{l}\text { Epineural using ultrasound } \\
\text { guidance, intravenous }\end{array}$ & Neuralgia & $\begin{array}{l}\text { Pain, depression severity, daily } \\
\text { functioning, adverse event }\end{array}$ & NCT04202783 \\
\hline
\end{tabular}

AD, Alzheimer's Disease; MSC, Mesenchymal Stem Cells.

may prove to enhance outcomes for those individuals vulnerable to age-related cognitive pathologies. In this context, the use of un-modified exosomes isolated from adipose mesenchymal stem cells is currently being investigated for AD-dementia in clinics (NCT04388982). Although the study is only exploring the safety and efficacy of exosome treatment in patients, data from secondary outcome measures that include $\mathrm{AD}$ biomarkers based in $\mathrm{A} \beta$ plasma/CSF measures, PET scans, and neuropsychological tests, may further encourage the development of engineered vesicles for the treatment of age-related cognitive decline. Table 2 summarizes ongoing clinical trials using exosome-based therapeutic interventions in neurodegenerative and neurological disorders assessing cognitive, disability, and daily functioning outcomes ${ }^{1}$.

\section{CONCLUSION}

The current composition proposes exosomes are uniquely suited to improve our mechanistic understanding as well as enhance patient outcomes for the growing public health challenge of age-related cognitive decline. We highlight how the analysis of exosomes can improve our understanding of

\footnotetext{
${ }^{1}$ http://www.clinicaltrials.gov
} 
varying mechanisms in age-related cognitive decline, including the role of miRNAs, neuroinflammation and aggregate-prone proteins (i.e., $A \beta$, pTau). Despite these contributions, we suggest specific areas of inquiry that warrant further interrogation, including the elucidation mechanisms in recipient cells that are modulated by exosomal miRNAs, the characterization of exosomal contents that are responsible for alterations in neuroinflammation and the examination of other aggregateprone peptides (e.g., TDP-43, $\alpha$-synuclein) in exosomes that may synergistically increase risk for late life cognitive impairment. Moreover, we discuss how exosomes might be used to enhance outcomes for elderly individuals by serving as reliable biomarkers and therapeutic agents.

To improve the reliability of studies going forward, consistent nomenclature coupled with protocol modifications that enhance the discrimination of EVs could be particularly effective. Due to similar biophysical properties (i.e., overlapping size, density, and protein compositions), isolation techniques developed for exosomes can inadvertently lead to results that are derived from samples containing a variety of different EVs (Théry et al., 2018; Witwer and Théry, 2019). Similarly, exosome-specific effects can be reported from protocols that fail to adequately purify EVs from nonvesicular components that can confound ensuing biochemical measurements (e.g., RNA-protein complexes) (Lötvall et al., 2014). To avoid different kinds of vesicles being labeled with the same terminology, MISEV guidelines suggest EVs should instead be labeled according to their size, biochemical composition and conditions/cellular origin (Théry et al., 2018). Several methodological alterations have also been suggested to improve accuracy in terminology, including the use of serum over plasma, and the use of brain derived exosomes rather than total exosomes (Xing et al., 2021). Moreover, technical aspects should also be considered for increasing reliability, including the standardization of exosomal extraction and isolation, where differences in protocols can otherwise lead to substantially divergent results both between as well as within procedures (e.g., immunoprecipitation, ultracentrifugation) (Martins et al., 2018; Patel et al., 2019; Brennan et al., 2020; Shtam et al., 2020). Similarly, investigations should employ parallel protocols for the handling and preservation of samples across experimental designs, given that alternative storage conditions can alter exosome stability (Cheng et al., 2019). Consistent nomenclature suggested by MISEV guidelines, protocol adjustments (i.e., using appropriate controls, characterizing vesicles with advanced microscopy, profiling protein composition etc.) and standardized technical procedures across studies may improve the reliability of exosome measurements and enhance their application in the context of age-related cognitive decline.

Several additional limitations hinder the further application of exosomes discussed herein. Notably, it remains unknown whether concurrent variation in exosomes and cognitive capacities is reflective of a causal or reverse-causal association. In other words, it is difficult to determine if exosomal differentiation contributes to divergent cognitive trajectories, or if such differences are secondary to other biological processes that otherwise increase risk for cognitive deterioration in aging. A lack of data measuring time-dependent variation in the profiles of neuronal exosomes contributes to this lack of understanding, and potentially inhibits researchers from adequately controlling for the effects of aging. Although a limited set of investigations have employed longitudinal designs (Fiandaca et al., 2015; Winston et al., 2016; Kapogiannis et al., 2019; Zhao et al., 2020), future studies should take steps to establish temporal precedence and determine the causal implications of exosomes in facilitating cognitive decline. Along with the call to establish causation, additional evidence is needed to discern the role of modifiable life factors that can lead to cognitive resiliency in aging, such as exercise, diet and cognitive stimulation (Duggan and Parikh, 2021). For example, our recent data in rodents has demonstrated that engagement on an attention demanding task during aging leads to the upregulation of transcripts linked to extracellular vesicles, suggesting exosome-related biochemical pathways could be important for inducing individual variation in cognitive resilience (Duggan et al., 2019). Another limitation is the need to examine alternative neurobiological mechanisms not discussed in the current composition. Indeed, data suggest individuals exhibiting cognitive deficits in aging maintain altered concentrations of exosomal proteins implicated in insulin signaling (Kapogiannis et al., 2015, 2019), lysosomal degradation/autophagy (Goetzl et al., 2015) as well as synaptic integrity (Goetzl et al., 2016a, 2018a; Winston et al., 2016, 2018; Agliardi et al., 2019; Jia et al., 2021). By addressing these limitations, researchers may gain a greater understanding of exosome-mediated regulation of miRNAs, neuroinflammation, and aggregate-prone proteins, while enhancing the potential for exosomes to serve as reliable biomarkers of cognitive decline and as nanocarriers to deliver therapeutic agents to the brain in neurodegenerative conditions.

\section{AUTHOR CONTRIBUTIONS}

MD and VP conceived and designed the study. MD and AL conducted the literature search. MD, AL, and VP wrote the manuscript. TF and MW edited the final manuscript. All authors have read and approved the manuscript.

\section{FUNDING}

The authors would like to acknowledge support from the National Institute on Aging (AG029592 and AG046580 to VP and AG037984 to TF) and the American Federation for Aging Research (VP). MD is currently supported by the Intramural Research Program of the NIH, National Institute on Aging. Publication of this article was funded in part by the Temple University Libraries Open Access Publishing Fund and the McKnight Brain Research Foundation. 


\section{REFERENCES}

Agliardi, C., Guerini, F. R., Zanzottera, M., Bianchi, A., Nemni, R., and Clerici, M. (2019). SNAP-25 in serum is carried by exosomes of neuronal origin and is a potential biomarker of Alzheimer's disease. Mol. Neurobiol. 56, 5792-5798. doi: 10.1007/s12035-019-1501-x

Aiello Bowles, E. J., Crane, P. K., Walker, R. L., Chubak, J., Lacroix, A. Z., Anderson, M. L., et al. (2019). Cognitive resilience to Alzheimer's disease pathology in the human brain. J. Alzheimers Dis. 68, 1071-1083. doi: 10.3233/JAD- 180942

Albert, M., Moss, M. B., Tanzi, R., and Jones, K. (2001). Preclinical prediction of AD using neuropsychological tests. J. Int. Neuropsychol. Soc. 7, 631-639. doi: $10.1017 /$ s1355617701755105

Albert, M., Zhu, Y., Moghekar, A., Mori, S., Miller, M. I., Soldan, A., et al. (2018). Predicting progression from normal cognition to mild cognitive impairment for individuals at 5 years. Brain 141, 877-887. doi: 10.1093/brain/awx365

Alexander, G. C., Emerson, S., and Kesselheim, A. S. (2021). Evaluation of aducanumab for Alzheimer disease: scientific evidence and regulatory review involving efficacy, safety, and futility. JAMA 325, 1717-1718. doi: 10.1001/jama. 2021.3854

Alfieri, M., Leone, A., and Ambrosone, A. (2021). Plant-derived nano and microvesicles for human health and therapeutic potential in nanomedicine. Pharmaceutics 13:498. doi: 10.3390/pharmaceutics13040498

Alvarez-Erviti, L., Seow, Y., Yin, H., Betts, C., Lakhal, S., and Wood, M. J. A. (2011). Delivery of siRNA to the mouse brain by systemic injection of targeted exosomes. Nat. Biotech. 29, 341-345. doi: 10.1038/nbt.1807

Alzheimer's Association (2020). Alzheimer's disease facts and figures. Alzheimers Dement. 16, 391-460.

Anderson, T. S., Ayanian, J. Z., Souza, J., and Landon, B. E. (2021). Representativeness of participants eligible to be enrolled in clinical trials of aducanumab for alzheimer disease compared with medicare beneficiaries with alzheimer disease and mild cognitive impairment. JAMA 326, 1627-1629. doi: 10.1001/jama.2021.15286

Apodaca, L. A., Baddour, A. A. D., Garcia, C. Jr., Alikhani, L., Giedzinski, E., $\mathrm{Ru}, \mathrm{N}$., et al. (2021). Human neural stem cell-derived extracellular vesicles mitigate hallmarks of Alzheimer's disease. Alzheimers Res. Ther. 13:57. doi: 10.1186/s13195-021-00791-x

Asada, H., Tomiyasu, H., Uchikai, T., Ishihara, G., Goto-Koshino, Y., Ohno, K., et al. (2019). Comprehensive analysis of miRNA and protein profiles within exosomes derived from canine lymphoid tumour cell lines. PLoS One 14:e0208567. doi: 10.1371/journal.pone.0208567

Asai, H., Ikezu, S., Tsunoda, S., Medalla, M., Luebke, J., Haydar, T., et al. (2015). Depletion of microglia and inhibition of exosome synthesis halt tau propagation. Nat. Neurosci. 18, 1584-1593. doi: 10.1038/nn.4132

Balasubramanian, A. B., Kawas, C. H., Peltz, C. B., Brookmeyer, R., and Corrada, M. M. (2012). Alzheimer disease pathology and longitudinal cognitive performance in the oldest-old with no dementia. Neurology 79, 915-921. doi: 10.1212/WNL.0b013e318266fc77

Balusu, S., Van Wonterghem, E., De Rycke, R., Raemdonck, K., Stremersch, S., Gevaert, K., et al. (2016). Identification of a novel mechanism of blood-brain communication during peripheral inflammation via choroid plexus-derived extracellular vesicles. EMBO Mol. Med. 8, 1162-1183. doi: 10.15252/emmm. 201606271

Banks, W. A., Sharma, P., Bullock, K. M., Hansen, K. M., Ludwig, N., and Whiteside, T. L. (2020). Transport of extracellular vesicles across the bloodbrain barrier: brain pharmacokinetics and effects of inflammation. Int. J. Mol. Sci. 21:4407. doi: 10.3390/ijms21124407

Barbagallo, C., Mostile, G., Baglieri, G., Giunta, F., Luca, A., Raciti, L., et al. (2020). Specific signatures of serum miRNAs as potential biomarkers to discriminate clinically similar neurodegenerative and vascular-related diseases. Cell. Mol. Neurobiol. 40, 531-546. doi: 10.1007/s10571-019-00751-y

Barter, J., Kumar, A., Bean, L., Ciesla, M., and Foster, T. C. (2021). Adulthood systemic inflammation accelerates the trajectory of age-related cognitive decline. Aging 13, 22092-22108. doi: 10.18632/aging.203588

Bodart-Santos, V., De Carvalho, L. R. P., de Godoy, M. A., Batista, A. F., Saraiva, L. M., Lima, L. G., et al. (2019). Extracellular vesicles derived from human Wharton's jelly mesenchymal stem cells protect hippocampal neurons from oxidative stress and synapse damage induced by amyloid- $\beta$ oligomers. Stem Cell Res. Ther. 10:332. doi: 10.1186/s13287-019-1432-5
Boyle, P. A., Wang, T., Yu, L., Wilson, R. S., Dawe, R., Arfanakis, K., et al. (2021). To what degree is late life cognitive decline driven by age-relatedneuropathologies? Brain 144, 2166-2175. doi: 10.1093/brain/awab092

Boyle, P. A., Wilson, R. S., Yu, L., Barr, A. M., Honer, W. G., Schneider, J. A., et al. (2013). Much of late life cognitive decline is not due to common neurodegenerative pathologies. Ann. Neurol. 74, 478-489. doi: 10.1002/ana. 23964

Brennan, K., Martin, K., Fitzgerald, S. P., O’sullivan, J., Wu, Y., Blanco, A., et al. (2020). A comparison of methods for the isolation and separation of extracellular vesicles from protein and lipid particles in human serum. Sci. Rep. 10:1039. doi: 10.1038/s41598-020-57497-7

Bullain, S., and Doody, R. (2020). What works and what does not work in Alzheimer's disease? From interventions on risk factors to anti-amyloid trials. J. Neurochem. 155, 120-136. doi: 10.1111/jnc.15023

Bulloj, A., Leal, M. C., Xu, H., Castaño, E. M., and Morelli, L. (2010). Insulindegrading enzyme sorting in exosomes: a secretory pathway for a key brain amyloid-beta degrading protease. J. Alzheimers Dis. 19, 79-95. doi: 10.3233/ JAD-2010-1206

Cha, D. J., Mengel, D., Mustapic, M., Liu, W., Selkoe, D. J., Kapogiannis, D., et al. (2019). miR-212 and miR-132 are downregulated in neurally derived plasma exosomes of Alzheimer's patients. Front. Neurosci. 13:1208. doi: 10.3389/fnins. 2019.01208

Chen, G. Y., and Nunez, G. (2010). Sterile inflammation: sensing and reacting to damage. Nat. Rev. Immunol. 10, 826-837. doi: 10.1038/nri2873

Cheng, L., Doecke, J. D., Sharples, R. A., Villemagne, V. L., Fowler, C. J., Rembach, A., et al. (2015). Prognostic serum miRNA biomarkers associated with Alzheimer's disease shows concordance with neuropsychological and neuroimaging assessment. Mol. Psychiatry 20, 1188-1196. doi: 10.1038/mp. 2014.127

Cheng, Y., Zeng, Q., Han, Q., and Xia, W. (2019). Effect of pH, temperature and freezing-thawing on quantity changes and cellular uptake of exosomes. Protein Cell 10, 295-299. doi: 10.1007/s13238-018-0529-4

Chevillet, J. R., Kang, Q., Ruf, I. K., Briggs, H. A., Vojtech, L. N., Hughes, S. M., et al. (2014). Quantitative and stoichiometric analysis of the microRNA content of exosomes. PNAS 111, 14888-14893.

ClinicalTrials.gov Database (2022). U.S. National Library of Medicine. Available online at: http://www.clinicaltrials.gov (accessed January 31, 2022).

Cong, M., Shen, M., Wu, X., Li, Y., Wang, L., He, Q., et al. (2021). Improvement of sensory neuron growth and survival via negatively regulating PTEN by miR-21$5 \mathrm{p}$-contained small extracellular vesicles from skin precursor-derived Schwann cells. Stem Cell Res. Ther. 12:80. doi: 10.1186/s13287-020-02125-4

Conlan, R. S., Pisano, S., Oliveira, M. I., Ferrari, M., and Mendes Pinto, I. (2017). Exosomes as reconfigurable therapeutic systems. Trends Mol. Med. 23, 636-650. doi: 10.1016/j.molmed.2017.05.003

Cribbs, D. H., Berchtold, N. C., Perreau, V., Coleman, P. D., Rogers, J., Tenner, A. J., et al. (2012). Extensive innate immune gene activation accompanies brain aging, increasing vulnerability to cognitive decline and neurodegeneration: a microarray study. J. Neuroinflam. 9:18. doi: 10.1186/1742-2094-9-179

Cui, G.-H., Guo, H. D., Li, H., Zhai, Y., Gong, Z. B., Wu, J., et al. (2019). RVG-modified exosomes derived from mesenchymal stem cells rescue memory deficits by regulating inflammatory responses in a mouse model of Alzheimer's disease. Immun. Ageing 16:10. doi: 10.1186/s12979-019-0150-2

Cui, G.-H., Wu, J., Mou, F.-F., Xie, W.-H., Wang, F.-B., Wang, Q.-L., et al. (2018). Exosomes derived from hypoxia-preconditioned mesenchymal stromal cells ameliorate cognitive decline by rescuing synaptic dysfunction and regulating inflammatory responses in APP/PS1 mice. FASEB J. 32, 654-668. doi: 10.1096/ fj.201700600R

Cunningham, C. (2013). Microglia and neurodegeneration: the role of systemic inflammation. Glia 61, 71-90. doi: 10.1002/glia.22350

de Godoy, M. A., Saraiva, L. M., De Carvalho, L. R. P., Vasconcelos-Dos-Santos, A., Beiral, H. J. V., Ramos, A. B., et al. (2018). Mesenchymal stem cells and cell-derived extracellular vesicles protect hippocampal neurons from oxidative stress and synapse damage induced by amyloid- $\beta$ oligomers. J. Biol. Chem. 293, 1957-1975. doi: 10.1074/jbc.M117.807180

Deming, Y., Filipello, F., Cignarella, F., Cantoni, C., Hsu, S., Mikesell, R., et al. (2019). The MS4A gene cluster is a key modulator of soluble TREM2 and Alzheimer's disease risk. Sci. Trans. Med. 11:eaau2291. doi: 10.1126/ scitranslmed.aau2291 
Ding, M., Shen, Y., Wang, P., Xie, Z., Xu, S., Zhu, Z., et al. (2018). Exosomes isolated from human umbilical cord mesenchymal stem cells alleviate neuroinflammation and reduce amyloid-beta deposition by modulating microglial activation in Alzheimer's disease. Neurochem. Res. 43, 2165-2177. doi: $10.1007 / \mathrm{s} 11064-018-2641-5$

Dinkins, M. B., Wang, G., and Bieberich, E. (2017). Sphingolipid-enriched extracellular vesicles and Alzheimer's disease: a decade of research. J. Alzheimers Dis. 60, 757-768. doi: 10.3233/JAD-160567

Domingues, H. S., Falcão, A. M., Mendes-Pinto, I., Salgado, A. J., and Teixeira, F. G. (2020). Exosome circuitry during (De)(Re)myelination of the central nervous system. Front. Cell. Dev. Biol. 8:483. doi: 10.3389/fcell.2020.00483

Dong, X., Zheng, D., and Nao, J. (2020). Circulating exosome microRNAs as diagnostic biomarkers of dementia. Front. Aging Neurosci. 12:580199. doi: 10. 3389/fnagi.2020.580199

Dong, Z., Gu, H., Guo, Q., Liang, S., Xue, J., Yao, F., et al. (2021). Profiling of serum exosome MiRNA reveals the potential of a MiRNA panel as diagnostic biomarker for Alzheimer's disease. Mol. Neurobiol. 58, 3084-3094. doi: 10.1007/ s12035-021-02323-y

Duggan, M. R., Joshi, S., Tan, Y. F., Slifker, M., Ross, E. A., Wimmer, M., et al. (2019). Transcriptomic changes in the prefrontal cortex of rats as a function of age and cognitive engagement. Neurobiol. Learn. Mem. 163:107035. doi: 10.1016/j.nlm.2019.107035

Duggan, M. R., and Parikh, V. (2021). Microglia and modifiable life factors: potential contributions to cognitive resilience in aging. Behav. Brain Res. 405:113207. doi: 10.1016/j.bbr.2021.113207

Elia, C. A., Tamborini, M., Rasile, M., Desiato, G., Marchetti, S., Swuec, P., et al. (2019). Intracerebral injection of extracellular vesicles from mesenchymal stem cells exerts reduced $A \beta$ plaque burden in early stages of a preclinical model of Alzheimer's disease. Cells 8:1059. doi: 10.3390/cells8091059

Elmore, M. R. P., Hohsfield, L. A., Kramár, E. A., Soreq, L., Lee, R. J., Pham, S. T., et al. (2018). Replacement of microglia in the aged brain reverses cognitive, synaptic, and neuronal deficits in mice. Aging Cell 17:e12832. doi: 10.1111/acel. 12832

Elsherbini, A., Kirov, A. S., Dinkins, M. B., Wang, G., Qin, H., Zhu, Z., et al. (2020a). Association of $A \beta$ with ceramide-enriched astrosomes mediates $A \beta$ neurotoxicity. Acta Neuropathol. Commun. 8:60.

Elsherbini, A., Qin, H., Zhu, Z., Tripathi, P., Crivelli, S. M., and Bieberich, E. (2020b). In vivo evidence of exosome-mediated A $\beta$ neurotoxicity. Acta Neuropathol. Commun. 8:100.

Espay, A. J., Vizcarra, J. A., Marsili, L., Lang, A. E., Simon, D. K., Merola, A., et al. (2019). Revisiting protein aggregation as pathogenic in sporadic Parkinson and Alzheimer diseases. Neurology 92, 329-337.

Fabbri, M., Paone, A., Calore, F., Galli, R., Gaudio, E., Santhanam, R., et al. (2012). MicroRNAs bind to Toll-like receptors to induce prometastatic inflammatory response. PNAS 109, E2110-E2116. doi: 10.1073/pnas.120941 4109

Fauré, J., Lachenal, G., Court, M., Hirrlinger, J., Chatellard-Causse, C., Blot, B., et al. (2006). Exosomes are released by cultured cortical neurones. Mol. Cell Neurosci. 31, 642-648. doi: 10.1016/j.mcn.2005.12.003

Fiandaca, M. S., Kapogiannis, D., Mapstone, M., Boxer, A., Eitan, E., Schwartz, J. B., et al. (2015). Identification of preclinical Alzheimer's disease by a profile of pathogenic proteins in neurally derived blood exosomes: a case-control study. Alzheimers Dement. 11, 600.e1-607.e1. doi: 10.1016/j.jalz.2014.06.008

Franceschi, C., and Campisi, J. (2014). Chronic inflammation (inflammaging) and its potential contribution to age-associated diseases. J. Gerontol. Ser. A Biol. Sci. Med. Sci. 69, S4-S9. doi: 10.1093/gerona/glu057

Frölich, L., Peters, O., Lewczuk, P., Gruber, O., Teipel, S. J., Gertz, H. J., et al. (2017). Incremental value of biomarker combinations to predict progression of mild cognitive impairment to Alzheimer's dementia. Alzheimers Res. Ther. 9:84. doi: 10.1186/s13195-017-0301-7

Frühbeis, C., Kuo-Elsner, W. P., Müller, C., Barth, K., Peris, L., Tenzer, S., et al. (2020). Oligodendrocytes support axonal transport and maintenance via exosome secretion. PLoS Biol. 18:e3000621. doi: 10.1371/journal.pbio.3000621

Fu, S., Wang, Y., Xia, X., and Zheng, J. C. (2020). Exosome engineering: current progress in cargo loading and targeted delivery. NanoImpact 20:100261.

Gallo, A., Tandon, M., Alevizos, I., and Illei, G. G. (2012). The majority of MicroRNAs detectable in serum and saliva is concentrated in exosomes. PLoS One 7:e0030679. doi: 10.1371/journal.pone.0030679
Gámez-Valero, A., Campdelacreu, J., Vilas, D., Ispierto, L., Reñé, R., Álvarez, R., et al. (2019). Exploratory study on microRNA profiles from plasma-derived extracellular vesicles in Alzheimer's disease and dementia with Lewy bodies. Transl. Neurodegener. 8:31. doi: 10.1186/s40035-019-0169-5

Glass, C. K., Saijo, K., Winner, B., Marchetto, M. C., and Gage, F. H. (2010). Mechanisms underlying inflammation in neurodegeneration. Cell 140, 918 934. doi: 10.1016/j.cell.2010.02.016

Goetzl, E. J., Abner, E. L., Jicha, G. A., Kapogiannis, D., and Schwartz, J. B. (2018a). Declining levels of functionally specialized synaptic proteins in plasma neuronal exosomes with progression of Alzheimer's disease. FASEB J. 32, 888-893. doi: 10.1096/fj.201700731R

Goetzl, E. J., Schwartz, J. B., Abner, E. L., Jicha, G. A., and Kapogiannis, D. (2018b). High complement levels in astrocyte-derived exosomes of Alzheimer disease. Ann. Neurol. 83, 544-552. doi: 10.1002/ana.25172

Goetzl, E. J., Boxer, A., Schwartz, J. B., Abner, E. L., Petersen, R. C., Miller, B. L., et al. (2015). Altered lysosomal proteins in neural-derived plasma exosomes in preclinical Alzheimer disease. Neurology 85, 40-47. doi: 10.1212/WNL. 0000000000001702

Goetzl, E. J., Kapogiannis, D., Schwartz, J. B., Lobach, I. V., Goetzl, L., Abner, E. L., et al. (2016a). Decreased synaptic proteins in neuronal exosomes of frontotemporal dementia and Alzheimer's disease. FASEB J. 30, 4141-4148. doi: 10.1096/fj.201600816R

Goetzl, E. J., Mustapic, M., Kapogiannis, D., Eitan, E., Lobach, I. V., Goetzl, L., et al. (2016b). Cargo proteins of plasma astrocyte-derived exosomes in Alzheimer's disease. FASEB J. 30, 3853-3859. doi: 10.1096/fj.201600756R

Goldberg, E. L., and Dixit, V. D. (2015). Drivers of age-related inflammation and strategies for healthspan extension. Immunol. Rev. 265, 63-74. doi: 10.1111/imr. 12295

Gouwens, L. K., Ismail, M. S., Rogers, V. A., Zeller, N. T., Garrad, E. C., Amtashar, F. S., et al. (2018). A $\beta 42$ protofibrils interact with and are trafficked through microglial-derived microvesicles. ACS Chem. Neurosci. 9, 1416-1425. doi: 10. 1021/acschemneuro.8b00029

Grigor'eva, A. E., Dyrkheeva, N. S., Bryzgunova, O. E., Tamkovich, S. N., Chelobanov, B. P., and Ryabchikova, E. I. (2017). Contamination of exosome preparations, isolated from biological fluids. Biomed. Khim. 63, 91-96. doi: 10.18097/PBMC2017630191

Gui, Y., Liu, H., Zhang, L., Lv, W., and Hu, X. (2015). Altered microRNA profiles in cerebrospinal fluid exosome in Parkinson disease and Alzheimer disease. Oncotarget 6, 37043-37053. doi: 10.18632/oncotarget.6158

Gullett, J. M., Chen, Z., O’shea, A., Akbar, M., Bian, J., Rani, A., et al. (2020). MicroRNA predicts cognitive performance in healthy older adults. Neurobiol. Aging 95, 186-194. doi: 10.1016/j.neurobiolaging.2020.07.023

Guo, L., Huang, Z., Huang, L., Liang, J., Wang, P., Zhao, L., et al. (2021). Surfacemodified engineered exosomes attenuated cerebral ischemia/reperfusion injury by targeting the delivery of quercetin towards impaired neurons. J. Nanobiotech. 19:141. doi: 10.1186/s12951-021-00879-4

Gupta, A., and Pulliam, L. (2014). Exosomes as mediators of neuroinflammation. J. Neuroinflam. 11:68. doi: 10.1186/1742-2094-11-68

Gurunathan, S., Kang, M. H., Jeyaraj, M., Qasim, M., and Kim, J. H. (2019). Review of the isolation, characterization, biological function, and multifarious therapeutic approaches of exosomes. Cells 8:36.

Haney, M. J., Klyachko, N. L., Zhao, Y., Gupta, R., Plotnikova, E. G., He, Z., et al. (2015). Exosomes as drug delivery vehicles for Parkinson's disease therapy. J. Control Release 207, 18-30.

Hayden, K. M., Reed, B. R., Manly, J. J., Tommet, D., Pietrzak, R. H., Chelune, G. J., et al. (2011). Cognitive decline in the elderly: an analysis of population heterogeneity. Age Ageing 40, 684-689. doi: 10.1093/ageing/afr101

He, P., Zhong, Z., Lindholm, K., Berning, L., Lee, W., Lemere, C., et al (2007). Deletion of tumor necrosis factor death receptor inhibits amyloid beta generation and prevents learning and memory deficits in Alzheimer's mice. J. Cell Biol. 178, 829-841. doi: 10.1083/jcb.200705042

Hessvik, N. P., and Llorente, A. (2018). Current knowledge on exosome biogenesis and release. Cell Mol. Life Sci. 75, 193-208. doi: 10.1007/s00018-017-2595-9

Holmes, C., Cunningham, C., Zotova, E., Woolford, J., Dean, C., Kerr, S., et al. (2009). Systemic inflammation and disease progression in Alzheimer disease. Neurology 73, 768-774. doi: 10.1212/wnl.0b013e3181b6bb95

Holstege, H., Hulsman, M., Charbonnier, C., Grenier-Boley, B., Quenez, O., Ahmad, S., et al. (2020). SORL1-variant carriers in ADES-ADSP: a higher 
level of variant pathogenicity associates with earlier age at onset of Alzheimer's disease. Alzheimers Dement. 16:e044492.

Huang, X. Y., Yuan, T. Z., Tschannen, M., Sun, Z. F., Jacob, H., Du, M. J., et al. (2013). Characterization of human plasma-derived exosomal RNAs by deep sequencing. BMC Genom. 14:319. doi: 10.1186/1471-2164-14-319

Huntzinger, E., and Izaurralde, E. (2011). Gene silencing by microRNAs: contributions of translational repression and mRNA decay. Nat. Rev. Genet. 12, 99-110. doi: 10.1038/nrg2936

Iguchi, Y., Eid, L., Parent, M., Soucy, G., Bareil, C., Riku, Y., et al. (2016). Exosome secretion is a key pathway for clearance of pathological TDP-43. Brain 139, 3187-3201. doi: 10.1093/brain/aww237

Ipsaro, J. J., and Joshua-Tor, L. (2015). From guide to target: molecular insights into eukaryotic RNA-interference machinery. Nat. Struct. Mol. Biol. 22, 20-28. doi: $10.1038 / \mathrm{nsmb} .2931$

Jack, C. R. Jr., Bennett, D. A., Blennow, K., Carrillo, M. C., Feldman, H. H., Frisoni, G. B., et al. (2016). A/T/N: an unbiased descriptive classification scheme for Alzheimer disease biomarkers. Neurology 87, 539-547. doi: 10.1212/WNL. 0000000000002923

Jack, C. R. Jr., Wiste, H. J., Therneau, T. M., Weigand, S. D., Knopman, D. S., Mielke, M. M., et al. (2019). Associations of amyloid, tau, and neurodegeneration biomarker profiles with rates of memory decline among individuals without dementia. JAMA 321, 2316-2325. doi: 10.1001/jama.2019. 7437

James, B. D., Wilson, R. S., Boyle, P. A., Trojanowski, J. Q., Bennett, D. A., and Schneider, J. A. (2016). TDP-43 stage, mixed pathologies, and clinical Alzheimer's-type dementia. Brain 139, 2983-2993. doi: 10.1093/brain/aww224

Janelidze, S., Mattsson, N., Palmqvist, S., Smith, R., Beach, T. G., Serrano, G. E., et al. (2020). Plasma P-tau181 in Alzheimer's disease: relationship to other biomarkers, differential diagnosis, neuropathology and longitudinal progression to Alzheimer's dementia. Nat. Med. 26, 379-386. doi: 10.1038/ s41591-020-0755-1

Jia, G., Han, Y., An, Y., Ding, Y., He, C., Wang, X., et al. (2018). NRP-1 targeted and cargo-loaded exosomes facilitate simultaneous imaging and therapy of glioma in vitro and in vivo. Biomaterials 178, 302-316. doi: 10.1016/j.biomaterials. 2018.06.029

Jia, L., Qiu, Q., Zhang, H., Chu, L., Du, Y., Zhang, J., et al. (2019). Concordance between the assessment of A $\beta 42, \mathrm{~T}$-tau, and P-T181-tau in peripheral blood neuronal-derived exosomes and cerebrospinal fluid. Alzheimers Dement. 15, 1071-1080. doi: 10.1016/j.jalz.2019.05.002

Jia, L., Zhu, M., Kong, C., Pang, Y., Zhang, H., Qiu, Q., et al. (2021). Blood neuroexosomal synaptic proteins predict Alzheimer's disease at the asymptomatic stage. Alzheimers Dement. 17, 49-60. doi: 10.1002/alz.12166

Joshi, P., Turola, E., Ruiz, A., Bergami, A., Libera, D. D., Benussi, L., et al. (2014). Microglia convert aggregated amyloid- $\beta$ into neurotoxic forms through the shedding of microvesicles. Cell Death Differ. 21, 582-593. doi: 10.1038/cdd. 2013.180

Kalluri, R., and LeBleu, V. S. (2020). The biology, function, and biomedical applications of exosomes. Science 367:eaau6977. doi: 10.1126/science.aau6977

Kapogiannis, D., Boxer, A., Schwartz, J. B., Abner, E. L., Biragyn, A., Masharani, U., et al. (2015). Dysfunctionally phosphorylated type 1 insulin receptor substrate in neural-derived blood exosomes of preclinical Alzheimer's disease. FASEB J. 29, 589-596. doi: 10.1096/fj.14-262048

Kapogiannis, D., Mustapic, M., Shardell, M. D., Berkowitz, S. T., Diehl, T. C., Spangler, R. D., et al. (2019). Association of extracellular vesicle biomarkers with Alzheimer disease in the baltimore longitudinal study of aging. JAMA Neurol. 76, 1340-1351. doi: 10.1001/jamaneurol.2019.2462

Katzman, R., Terry, R., Deteresa, R., Brown, T., Davies, P., Fuld, P., et al. (1988). Clinical, pathological, and neurochemical changes in dementia: a subgroup with preserved mental status and numerous neocortical plaques. Ann. Neurol. 23, 138-144. doi: 10.1002/ana.410230206

Kawas, C. H., Kim, R. C., Sonnen, J. A., Bullain, S. S., Trieu, T., and Corrada, M. M. (2015). Multiple pathologies are common and related to dementia in the oldest-old: the 90+ Study. Neurology 85, 535-542. doi: 10.1212/WNL. 0000000000001831

Khan, M. B., Lang, M. J., Huang, M. B., Raymond, A., Bond, V. C., Shiramizu, B., et al. (2016). Nef exosomes isolated from the plasma of individuals with HIVassociated dementia (HAD) can induce $\mathrm{A} \beta(1-42)$ secretion in SH-SY5Y neural cells. J. Neurovirol. 22, 179-190. doi: 10.1007/s13365-015-0383-6
Kim, G., Kim, M., Lee, Y., Byun, J. W., Hwang, D. W., and Lee, M. (2020). Systemic delivery of microRNA-21 antisense oligonucleotides to the brain using T7peptide decorated exosomes. J. Control Release 317, 273-281. doi: 10.1016/j. jconrel.2019.11.009

Knopman, D. S., Jones, D. T., and Greicius, M. D. (2021). Failure to demonstrate efficacy of aducanumab: an analysis of the EMERGE and ENGAGE trials as reported by Biogen, December 2019. Alzheimers Dement. 17, 696-701.

Krämer-Albers, E. M., Bretz, N., Tenzer, S., Winterstein, C., Möbius, W., Berger, H., et al. (2007). Oligodendrocytes secrete exosomes containing major myelin and stress-protective proteins: trophic support for axons? Proteomics Clin. Appl. 1, 1446-1461. doi: 10.1002/prca.200700522

Kreisl, W. C., Lyoo, C. H., Mcgwier, M., Snow, J., Jenko, K. J., Kimura, N., et al. (2013). In vivo radioligand binding to translocator protein correlates with severity of Alzheimer's disease. Brain 136, 2228-2238. doi: 10.1093/brain/ awt145

Kučuk, N., Primožič, M., Knez, Ž, and Leitgeb, M. (2021). Exosomes engineering and their roles as therapy delivery tools, therapeutic targets, and biomarkers. Int. J. Mol. Sci. 22:9543. doi: 10.3390/ijms 22179543

Kumar, A., Hughes, T. M., Craft, S., and Deep, G. (2020). A novel approach to isolate brain-cell-derived exosomes from plasma to better understand pathogenesis of Alzheimer's disease. Alzheimers Dement. 16:e044894.

Kumar, A., Kim, S., Su, Y., Sharma, M., Kumar, P., Singh, S., et al. (2021). Brain cellderived exosomes in plasma serve as neurodegeneration biomarkers in male cynomolgus monkeys self-administrating oxycodone. EBioMedicine 63:103192. doi: 10.1016/j.ebiom.2020.103192

Lanoiselée, H. M., Nicolas, G., Wallon, D., Rovelet-Lecrux, A., Lacour, M., Rousseau, S., et al. (2017). APP, PSEN1, and PSEN2 mutations in early-onset Alzheimer disease: a genetic screening study of familial and sporadic cases. PLoS Med. 14:e1002270. doi: 10.1371/journal.pmed.1002270

Lee, M., Ban, J.-J., Yang, S., Im, W., and Kim, M. (2018). The exosome of adiposederived stem cells reduces $\beta$-amyloid pathology and apoptosis of neuronal cells derived from the transgenic mouse model of Alzheimer's disease. Brain Res. 1691, 87-93. doi: 10.1016/j.brainres.2018.03.034

Li, B., Liu, J., Gu, G., Han, X., Zhang, Q., and Zhang, W. (2020). Impact of neural stem cell-derived extracellular vesicles on mitochondrial dysfunction, sirtuin 1 level, and synaptic deficits in Alzheimer's disease. J. Neurochem. 154:e15001. doi: 10.1111/jnc.15001

Li, Y., Zheng, Q., Bao, C., Li, S., Guo, W., Zhao, J., et al. (2015). Circular RNA is enriched and stable in exosomes: a promising biomarker for cancer diagnosis. Cell Res. 25, 981-984. doi: 10.1038/cr.2015.82

Lim, C. Z. J., Zhang, Y., Chen, Y., Zhao, H., Stephenson, M. C., Ho, N. R. Y., et al. (2019). Subtyping of circulating exosome-bound amyloid $\beta$ reflects brain plaque deposition. Nat. Commun. 10:1144. doi: 10.1038/s41467-019-09030-2

Liu, C. G., Song, J., Zhang, Y. Q., and Wang, P. C. (2014). MicroRNA-193b is a regulator of amyloid precursor protein in the blood and cerebrospinal fluid derived exosomal microRNA-193b is a biomarker of Alzheimer's disease. Mol. Med. Rep. 10, 2395-2400. doi: 10.3892/mmr.2014.2484

Long, J. M., and Holtzman, D. M. (2019). Alzheimer disease: an update on pathobiology and treatment strategies. Cell 179, 312-339. doi: 10.1016/j.cell. 2019.09.001

Lötvall, J., Hill, A. F., Hochberg, F., Buzás, E. I., Di Vizio, D., Gardiner, C., et al. (2014). Minimal experimental requirements for definition of extracellular vesicles and their functions: a position statement from the International Society for Extracellular Vesicles. J. Extracell. Vesicles 3:26913. doi: 10.3402/jev.v3. 26913

Luan, X., Sansanaphongpricha, K., Myers, I., Chen, H., Yuan, H., and Sun, D. (2017). Engineering exosomes as refined biological nanoplatforms for drug delivery. Acta Pharmacol. Sin. 38, 754-763. doi: 10.1038/aps.2017.12

Lugli, G., Cohen, A. M., Bennett, D. A., Shah, R. C., Fields, C. J., Hernandez, A. G., et al. (2015). Plasma exosomal miRNAs in persons with and without Alzheimer disease: altered expression and prospects for biomarkers. PLoS One 10:e0139233. doi: 10.1371/journal.pone. 0139233

Martins, S. T., Catita, J., Martins Rosa, A. B. I, da Cruz, E., Silva, O., and Henriques, A. G. (2018). Exosome isolation from distinct biofluids using precipitation and column-based approaches. PLoS One 13:e0198820. doi: 10.1371/journal.pone. 0198820 
Mathieu, C., Pappu, R. V., and Taylor, J. P. (2020). Beyond aggregation: pathological phase transitions in neurodegenerative disease. Science 370, 56-60. doi: $10.1126 /$ science.abb8032

Mathieu, M., Martin-Jaular, L., Lavieu, G., and Théry, C. (2019). Specificities of secretion and uptake of exosomes and other extracellular vesicles for cell-to-cell communication. Nat. Cell Biol. 21, 9-17. doi: 10.1038/s41556-018-0250-9

McKeever, P. M., Schneider, R., Taghdiri, F., Weichert, A., Multani, N., Brown, R. A., et al. (2018). MicroRNA expression levels are altered in the cerebrospinal fluid of patients with young-onset Alzheimer's disease. Mol. Neurobiol. 55, 8826-8841. doi: 10.1007/s12035-018-1032-x

Micci, M.-A., Krishnan, B., Bishop, E., Zhang, W.-R., Guptarak, J., Grant, A., et al. (2019). Hippocampal stem cells promotes synaptic resistance to the dysfunctional impact of amyloid beta oligomers via secreted exosomes. Mol. Neurodegen. 14:25. doi: 10.1186/s13024-019-0322-8

Mirza, A. H., Kaur, S., Nielsen, L. B., Størling, J., Yarani, R., Roursgaard, M., et al. (2019). Breast milk-derived extracellular vesicles enriched in exosomes from mothers with type 1 diabetes contain aberrant levels of microRNAs. Front. Immunol. 10:2543. doi: 10.3389/fimmu.2019.02543

Mitka, M. (2013). PET imaging for Alzheimer disease: are its benefits worth the cost? JAMA 309, 1099-1100. doi: 10.1001/jama.2013.2101

Morris, J. C., Storandt, M., Mckeel, D. W. Jr., Rubin, E. H., Price, J. L., Grant, E. A., et al. (1996). Cerebral amyloid deposition and diffuse plaques in "normal" aging: evidence for presymptomatic and very mild Alzheimer's disease. Neurology 46, 707-719. doi: 10.1212/wnl.46.3.707

Mulcahy, L. A., Pink, R. C., and Carter, D. R. (2014). Routes and mechanisms of extracellular vesicle uptake. J. Extracell. Vesicles 3:24641. doi: 10.3402/jev.v3. 24641

Mustapic, M., Eitan, E., Werner, J. K., Berkowitz, S. T., Lazaropoulos, M. P., Tran, J., et al. (2017). Plasma extracellular vesicles enriched for neuronal origin: a potential window into brain pathologic processes. Front. Neurosci. 11:278. doi: $10.3389 /$ fnins.2017.00278

Nakase, I., and Futaki, S. (2015). Combined treatment with a pH-sensitive fusogenic peptide and cationic lipids achieves enhanced cytosolic delivery of exosomes. Sci. Rep. 5:10112. doi: 10.1038/srep 10112

Nam, E., Lee, Y. B., Moon, C., and Chang, K. A. (2020). Serum tau proteins as potential biomarkers for the assessment of Alzheimer's disease progression. Int. J. Mol. Sci. 21:5007. doi: 10.3390/ijms21145007

Negash, S., Wilson, R. S., Leurgans, S. E., Wolk, D. A., Schneider, J. A., Buchman, A. S., et al. (2013). Resilient brain aging: characterization of discordance between Alzheimer's disease pathology and cognition. Curr. Alzheimer Res. 10, 844-851. doi: 10.2174/15672050113109990157

Ngandu, T., Lehtisalo, J., Solomon, A., Levälahti, E., Ahtiluoto, S., Antikainen, R., et al. (2015). A 2 year multidomain intervention of diet, exercise, cognitive training, and vascular risk monitoring versus control to prevent cognitive decline in at-risk elderly people (FINGER): a randomised controlled trial. Lancet 385, 2255-2263. doi: 10.1016/S0140-6736(15)60461-5

Ngolab, J., Trinh, I., Rockenstein, E., Mante, M., Florio, J., Trejo, M., et al. (2017). Brain-derived exosomes from dementia with Lewy bodies propagate $\alpha$-synuclein pathology. Acta Neuropathol. Commun. 5:46.

Niu, M., Li, Y., Li, G., Zhou, L., Luo, N., Yao, M., et al. (2020). A longitudinal study on $\alpha$-synuclein in plasma neuronal exosomes as a biomarker for Parkinson's disease development and progression. Euro J. Neurol. 27, 967-974. doi: 10.1111/ ene. 14208

Nogueras-Ortiz, C. J., Mahairaki, V., Delgado-Peraza, F., Das, D., Avgerinos, K., Eren, E., et al. (2020). Astrocyte- and neuron-derived extracellular vesicles from Alzheimer's disease patients effect complement-mediated neurotoxicity. Cells 9:1618. doi: $10.3390 /$ cells 9071618

Norman, M., Ter-Ovanesyan, D., Trieu, W., Lazarovits, R., Kowal, E. J. K., Lee, J. H., et al. (2021). L1CAM is not associated with extracellular vesicles in human cerebrospinal fluid or plasma. Nat. Methods 18, 631-634. doi: 10.1038/s41592021-01174-8

Novikova, G., Andrews, S. J., Renton, A. E., and Marcora, E. (2021). Beyond association: successes and challenges in linking non-coding genetic variation to functional consequences that modulate Alzheimer's disease risk. Mol. Neurodegen. 16:27. doi: 10.1186/s13024-021-00449-0

O'Brien, J., Hayder, H., Zayed, Y., and Peng, C. (2018). Overview of MicroRNA biogenesis, mechanisms of actions, and circulation. Front. Endocrinol. 9:402. doi: $10.3389 /$ fendo.2018.00402
O’Brien, K., Breyne, K., Ughetto, S., Laurent, L. C., and Breakefield, X. O. (2020). RNA delivery by extracellular vesicles in mammalian cells and its applications. Nat. Rev. Mol. Cell Biol. 21, 585-606. doi: 10.1038/s41580-0200251-y

Ohno, S.-I., Takanashi, M., Sudo, K., Ueda, S., Ishikawa, A., Matsuyama, N., et al. (2013). Systemically injected exosomes targeted to EGFR deliver antitumor MicroRNA to breast cancer cells. Mol. Ther. 21, 185-191. doi: 10.1038/mt.2012. 180

Palmqvist, S., Janelidze, S., Quiroz, Y. T., Zetterberg, H., Lopera, F., Stomrud, E., et al. (2020). Discriminative accuracy of plasma Phospho-tau217 for alzheimer disease vs other neurodegenerative disorders. JAMA 324, 772-781. doi: 10.1001/ jama.2020.12134

Pardridge, W. M. (2020). Treatment of Alzheimer's disease and blood-brain barrier drug delivery. Pharmaceuticals 13:394.

Patel, G. K., Khan, M. A., Zubair, H., Srivastava, S. K., Khushman, M. D., Singh, S., et al. (2019). Comparative analysis of exosome isolation methods using culture supernatant for optimum yield, purity and downstream applications. Sci. Rep. 9:5335. doi: 10.1038/s41598-019-41800-2

Patron, J., Serra-Cayuela, A., Han, B., Li, C., and Wishart, D. S. (2019). Assessing the performance of genome-wide association studies for predicting disease risk. PLoS One 14:e0220215. doi: 10.1371/journal.pone.0220215

Pêche, H., Renaudin, K., Beriou, G., Merieau, E., Amigorena, S., and Cuturi, M. C. (2006). Induction of tolerance by exosomes and short-term immunosuppression in a fully MHC-mismatched rat cardiac allograft model. Am. J. Transpl. 6, 1541-1550. doi: 10.1111/j.1600-6143.2006.01344.x

Perrotte, M., Haddad, M., Le Page, A., Frost, E. H., Fulöp, T., and Ramassamy, C. (2020). Profile of pathogenic proteins in total circulating extracellular vesicles in mild cognitive impairment and during the progression of Alzheimer's disease. Neurobiol. Aging 86, 102-111. doi: 10.1016/j.neurobiolaging.2019.10.010

Perut, F., Roncuzzi, L., Avnet, S., Massa, A., Zini, N., Sabbadini, S., et al. (2021). Strawberry-derived exosome-like nanoparticles prevent oxidative stress in human mesenchymal stromal cells. Biomolecules 11:87. doi: 10.3390/ biom 11010087

Pisitkun, T., Shen, R. F., and Knepper, M. A. (2004). Identification and proteomic profiling of exosomes in human urine. PNAS 101, 13368-13373. doi: 10.1073/ pnas. 0403453101

Polanco, J. C., Hand, G. R., Briner, A., Li, C., and Götz, J. (2021). Exosomes induce endolysosomal permeabilization as a gateway by which exosomal tau seeds escape into the cytosol. Acta Neuropathol. 141, 235-256. doi: 10.1007/s00401020-02254-3

Potolicchio, I., Carven, G. J., Xu, X., Stipp, C., Riese, R. J., Stern, L. J., et al. (2005). Proteomic analysis of microglia-derived exosomes: metabolic role of the aminopeptidase CD13 in neuropeptide catabolism. J. Immunol. 175, 22372243. doi: 10.4049/jimmunol.175.4.2237

Qi, H., Liu, C., Long, L., Ren, Y., Zhang, S., Chang, X., et al. (2016). Blood exosomes endowed with magnetic and targeting properties for cancer therapy. ACS Nano 10, 3323-3333. doi: 10.1021/acsnano.5b06939

Qi, Y., Guo, L., Jiang, Y., Shi, Y., Sui, H., and Zhao, L. (2020). Brain delivery of quercetin-loaded exosomes improved cognitive function in $\mathrm{AD}$ mice by inhibiting phosphorylated tau-mediated neurofibrillary tangles. Drug Deliv. 27, 745-755. doi: 10.1080/10717544.2020.1762262

Rahimi, J., and Kovacs, G. G. (2014). Prevalence of mixed pathologies in the aging brain. Alzheimers Res. Ther. 6:82. doi: 10.1186/s13195-014-0082-1

Rani, A., O'shea, A., Ianov, L., Cohen, R. A., Woods, A. J., and Foster, T. C. (2017). miRNA in circulating microvesicles as biomarkers for age-related cognitive decline. Front. Aging Neurosci. 9:323. doi: 10.3389/fnagi.2017.00323

Rani, K., Mukherjee, R., Singh, E., Kumar, S., Sharma, V., Vishwakarma, P., et al. (2019). Neuronal exosomes in saliva of Parkinson's disease patients: a pilot study. Parkinson. Relat. Disord. 67, 21-23. doi: 10.1016/j.parkreldis.2019. 09.008

Ransohoff, R. M. (2016). How neuroinflammation contributes to neurodegeneration. Science 353, 777-783.

Ransohoff, R. M., and Perry, V. H. (2009). Microglial physiology: unique stimuli, specialized responses. Annu. Rev. Immunol. 27, 119-145. doi: 10.1146/annurev. immunol.021908.132528

Rea, I. M., Gibson, D. S., Mcgilligan, V., Mcnerlan, S. E., Alexander, H. D., and Ross, O. A. (2018). Age and age-related diseases: role of inflammation triggers and cytokines. Front. Immunol. 9:586. doi: 10.3389/fimmu.2018.00586 
Riancho, J., Vázquez-Higuera, J. L., Pozueta, A., Lage, C., Kazimierczak, M., Bravo, M., et al. (2017). MicroRNA profile in patients with Alzheimer's disease: analysis of miR-9-5p and miR-598 in raw and exosome enriched cerebrospinal fluid samples. J. Alzheimers Dis. 57, 483-491. doi: 10.3233/JAD-161179

Rice, L., and Bisdas, S. (2017). The diagnostic value of FDG and amyloid PET in Alzheimer's disease-a systematic review. Eur. J. Radiol. 94, 16-24. doi: 10.1016/ j.ejrad.2017.07.014

Ruan, Z., Pathak, D., Venkatesan Kalavai, S., Yoshii-Kitahara, A., Muraoka, S., Bhatt, N., et al. (2020). Alzheimer's disease brain-derived extracellular vesicles spread tau pathology in interneurons. Brain 144, 288-309.

Sabbagh, M. N., Lue, L.-F., Fayard, D., and Shi, J. (2017). Increasing precision of clinical diagnosis of Alzheimer's disease using a combined algorithm incorporating clinical and novel biomarker data. Neurol. Ther. 6, 83-95. doi: 10.1007/s40120-017-0069-5

Salloway, S., Chalkias, S., Barkhof, F., Burkett, P., Barakos, J., Purcell, D., et al. (2022). Amyloid-related imaging abnormalities in 2 phase 3 studies evaluating aducanumab in patients with early Alzheimer disease. JAMA Neurol. 79, 13-21. doi: 10.1001/jamaneurol.2021.4161

Sardar Sinha, M., Ansell-Schultz, A., Civitelli, L., Hildesjö, C., Larsson, M., Lannfelt, L., et al. (2018). Alzheimer's disease pathology propagation by exosomes containing toxic amyloid-beta oligomers. Acta Neuropathol. 136, 41-56. doi: 10.1007/s00401-018-1868-1

Schneider, J. A., Arvanitakis, Z., Bang, W., and Bennett, D. A. (2007). Mixed brain pathologies account for most dementia cases in community-dwelling older persons. Neurology 69, 2197-2204. doi: 10.1212/01.wnl.0000271090.28148.24

Seifan, A., and Isaacson, R. (2015). The Alzheimer's prevention clinic at weill cornell medical college / New York - presbyterian hospital: risk stratification and personalized early intervention. J. Prev. Alzheimers Dis. 2, 254-266. doi: 10.14283/jpad.2015.81

Serpente, M., Fenoglio, C., D'anca, M., Arcaro, M., Sorrentino, F., Visconte, C., et al. (2020). MiRNA profiling in plasma neural-derived small extracellular vesicles from patients with Alzheimer's disease. Cells 9:1443. doi: 10.3390/cells9061443

Shtam, T., Evtushenko, V., Samsonov, R., Zabrodskaya, Y., Kamyshinsky, R., Zabegina, L., et al. (2020). Evaluation of immune and chemical precipitation methods for plasma exosome isolation. PLoS One 15:e0242732. doi: 10.1371/ journal.pone.0242732

Smyth, T., Petrova, K., Payton, N. M., Persaud, I., Redzic, J. S., Graner, M. W., et al. (2014). Surface functionalization of exosomes using click chemistry. Bioconjugate Chem. 25, 1777-1784. doi: 10.1021/bc500291r

Song, J., Huang, J., Chen, X., Teng, X., Song, Z., Xing, Y., et al. (2016). Donorderived exosomes induce specific regulatory $\mathrm{T}$ cells to suppress immune inflammation in the allograft heart. Sci. Rep. 6:20077.

Suire, C. N., Eitan, E., Shaffer, N. C., Tian, Q., Studenski, S., Mattson, M. P., et al. (2017). Walking speed decline in older adults is associated with elevated pro-BDNF in plasma extracellular vesicles. Exp. Gerontol. 98, 209-216. doi: 10.1016/j.exger.2017.08.024

Sun, D., Zhuang, X., Zhang, S., Deng, Z. B., Grizzle, W., Miller, D., et al. (2013). Exosomes are endogenous nanoparticles that can deliver biological information between cells. Adv. Drug Deliv. Rev. 65, 342-347. doi: 10.1016/j.addr.2012.07. 002

Sun, R., Wang, H., Shi, Y., Gao, D., Sun, Z., Chen, Z., et al. (2019). A pilot study of urinary exosomes in Alzheimer's disease. Neurodegener. Dis. 19, 184-191. doi: 10.1159/000505851

Teruel-Montoya, R., Luengo-Gil, G., Vallejo, F., Yuste, J. E., Bohdan, N., GarcíaBarberá, N., et al. (2019). Differential miRNA expression profile and proteome in plasma exosomes from patients with paroxysmal nocturnal hemoglobinuria. Sci. Rep. 9:3611. doi: 10.1038/s41598-019-40453-5

Thakur, B. K., Zhang, H., Becker, A., Matei, I., Huang, Y., Costa-Silva, B., et al. (2014). Double-stranded DNA in exosomes: a novel biomarker in cancer detection. Cell Res. 24, 766-769. doi: 10.1038/cr.2014.44

Théry, C., Witwer, K. W., Aikawa, E., Alcaraz, M. J., Anderson, J. D., Andriantsitohaina, R., et al. (2018). Minimal information for studies of extracellular vesicles 2018 (MISEV2018): a position statement of the International Society for Extracellular Vesicles and update of the MISEV2014 guidelines. J. Extracell. Vesicles 7:1535750. doi: 10.1080/20013078.2018. 1535750

Thijssen, E. H., La Joie, R., Wolf, A., Strom, A., Wang, P., Iaccarino, L., et al. (2020). Diagnostic value of plasma phosphorylated tau181 in Alzheimer's disease and frontotemporal lobar degeneration. Nat. Med. 26, 387-397. doi: 10.1038/s41591-020-0762-2

Thomi, G., Surbek, D., Haesler, V., Joerger-Messerli, M., and Schoeberlein, A. (2019). Exosomes derived from umbilical cord mesenchymal stem cells reduce microglia-mediated neuroinflammation in perinatal brain injury. Stem Cell Res. Ther. 10:105. doi: 10.1186/s13287-019-1207-z

Tkach, M., and Thery, C. (2016). Communication by extracellular vesicles: where we are and where we need to go. Cell 164, 1226-1232. doi: 10.1016/j.cell.2016. 01.043

Tricarico, C., Clancy, J., and D'souza-Schorey, C. (2017). Biology and biogenesis of shed microvesicles. Small GTPases 8, 220-232. doi: 10.1080/21541248.2016. 1215283

Umezu, T., Ohyashiki, K., Kuroda, M., and Ohyashiki, J. H. (2013). Leukemia cell to endothelial cell communication via exosomal miRNAs. Oncogene 32, 2747-2755. doi: 10.1038/onc.2012.295

Van Cauwenberghe, C., Van Broeckhoven, C., and Sleegers, K. (2016). The genetic landscape of Alzheimer disease: clinical implications and perspectives. Genet. Med. 18, 421-430. doi: 10.1038/gim.2015.117

van Niel, G., D'angelo, G., and Raposo, G. (2018). Shedding light on the cell biology of extracellular vesicles. Nat. Rev. Mol. Cell Biol. 19, 213-228. doi: 10.1038/nrm. 2017.125

Wang, S.-S., Jia, J., and Wang, Z. (2018). Mesenchymal stem cell-derived extracellular vesicles suppresses iNOS expression and ameliorates neural impairment in Alzheimer's disease mice. J. Alzheimers Dis. 61, 1005-1013. doi: 10.3233/JAD- 170848

Wang, Y., Balaji, V., Kaniyappan, S., Krüger, L., Irsen, S., Tepper, K., et al. (2017). The release and trans-synaptic transmission of Tau via exosomes. Mol. Neurodegen. 12:5. doi: 10.1186/s13024-016-0143-y

Wei, H., Xu, Y., Chen, Q., Chen, H., Zhu, X., and Li, Y. (2020). Mesenchymal stem cell-derived exosomal miR-223 regulates neuronal cell apoptosis. Cell Death Dis. 11:290.

Wei, H., Xu, Y., Xu, W., Zhou, Q., Chen, Q., Yang, M., et al. (2018). Serum exosomal miR-223 serves as a potential diagnostic and prognostic biomarker for dementia. Neuroscience 379, 167-176. doi: 10.1016/j.neuroscience.2018.03.016

Weigand, A. J., Eglit, G. M. L., Maass, A., and Bondi, M. W. (2020). What's the cut-point? A systematic review of tau pet thresholding methods. Alzheimers Dement. 16:e046270.

White, L. R., Edland, S. D., Hemmy, L. S., Montine, K. S., Zarow, C., Sonnen, J. A., et al. (2016). Neuropathologic comorbidity and cognitive impairment in the Nun and Honolulu-Asia Aging Studies. Neurology 86, 1000-1008. doi: 10.1212/WNL.0000000000002480

Widmann, C. N., and Heneka, M. T. (2014). Long-term cerebral consequences of sepsis. Lancet Neurol. 13, 630-636. doi: 10.1016/S1474-4422(14)70017-1

Wilson, R. S., Beckett, L. A., Barnes, L. L., Schneider, J. A., Bach, J., Evans, D. A., et al. (2002). Individual differences in rates of change in cognitive abilities of older persons. Psychol. Aging 17, 179-193. doi: 10.1037/0882-7974.17.2.179

Winston, C. N., Aulston, B., Rockenstein, E. M., Adame, A., Prikhodko, O., Dave, K. N., et al. (2019). Neuronal exosome-derived human tau is toxic to recipient mouse neurons in vivo. J. Alzheimers Dis. 67, 541-553. doi: 10.3233/JAD180776

Winston, C. N., Goetzl, E. J., Akers, J. C., Carter, B. S., Rockenstein, E. M., Galasko, D., et al. (2016). Prediction of conversion from mild cognitive impairment to dementia with neuronally derived blood exosome protein profile. Alzheimers Dement. 3, 63-72. doi: 10.1016/j.dadm.2016.04.001

Winston, C. N., Goetzl, E. J., Baker, L. D., Vitiello, M. V., and Rissman, R. A. (2018). Growth hormone-releasing hormone modulation of neuronal exosome biomarkers in mild cognitive impairment. J. Alzheimers Dis. 66, 971-981. doi: 10.3233/JAD- 180302

Witwer, K. W., and Théry, C. (2019). Extracellular vesicles or exosomes? On primacy, precision, and popularity influencing a choice of nomenclature. J. Extracell. Vesicles 8:1648167. doi: 10.1080/20013078.2019.1648167

Wong, W. T. (2013). Microglial aging in the healthy CNS: phenotypes, drivers, and rejuvenation. Front. Cell Neurosci. 7:22. doi: 10.3389/fncel.2013.00022

Wyss-Coray, T., and Rogers, J. (2012). Inflammation in Alzheimer disease-a brief review of the basic science and clinical literature. Cold Spring Harb. Perspect. Med. 2:23. doi: 10.1101/cshperspect.a006346

Xing, W., Gao, W., Lv, X., Xu, X., Zhang, Z., Yan, J., et al. (2021). The diagnostic value of exosome-derived biomarkers in Alzheimer's disease and mild cognitive 
impairment: a meta-analysis. Front. Aging Neurosci. 13:637218. doi: 10.3389/ fnagi.2021.637218

Yamazaki, Y., Zhao, N., Caulfield, T. R., Liu, C.-C., and Bu, G. (2019). Apolipoprotein E and Alzheimer disease: pathobiology and targeting strategies. Nat. Rev. Neurol. 15, 501-518. doi: 10.1038/s41582-019-0228-7

Yang, J., Zhang, X. F., Chen, X. J., Wang, L., and Yang, G. D. (2017). Exosome Mediated Delivery of miR-124 Promotes Neurogenesis after Ischemia. Mol. Ther. Nucl. Acids 7, 278-287. doi: 10.1016/j.omtn.2017.04.010

Yang, L., Zhai, Y., Hao, Y., Zhu, Z., and Cheng, G. (2020). The regulatory functionality of exosomes derived from hUMSCs in 3D culture for Alzheimer's disease therapy. Small 16:1906273. doi: 10.1002/smll.201906273

Yang, T., Liu, C. G., Gao, S. C., Zhang, Y., and Wang, P. C. (2018). The serum exosome derived MicroRNA-135a,-193b, and-384 were potential Alzheimer's disease biomarkers. Biomed. Environ. Sci. 31, 87-96. doi: 10.3967/bes2018.011

Ye, Z., Sun, B., Mi, X., and Xiao, Z. (2020). Gene co-expression network for analysis of plasma exosomal miRNAs in the elderly as markers of aging and cognitive decline. PeerJ 8:e8318. doi: 10.7717/peerj.8318

Yuan, D., Zhao, Y., Banks, W. A., Bullock, K. M., Haney, M., Batrakova, E., et al. (2017). Macrophage exosomes as natural nanocarriers for protein delivery to inflamed brain. Biomaterials 142, 1-12. doi: 10.1016/j.biomaterials.2017.07.011

Yuyama, K., Sun, H., Sakai, S., Mitsutake, S., Okada, M., Tahara, H., et al. (2014). Decreased amyloid- $\beta$ pathologies by intracerebral loading of glycosphingolipidenriched exosomes in Alzheimer model mice. J. Biol. Chem. 289, 24488-24498. doi: 10.1074/jbc.M114.577213

Zhang, N., Gu, D., Meng, M., and Gordon, M. L. (2020). TDP-43 is elevated in plasma neuronal-derived exosomes of patients with Alzheimer's disease. Front. Aging Neurosci. 12:166. doi: 10.3389/fnagi.2020.00166

Zhang, Z., Zou, X., Zhang, R., Xie, Y., Feng, Z., Li, F., et al. (2021). Human umbilical cord mesenchymal stem cell-derived exosomal miR-146a-5p reduces microglial-mediated neuroinflammation via suppression of the IRAK1/TRAF6 signaling pathway after ischemic stroke. Aging 13, 3060-3079. doi: 10.18632/ aging.202466
Zhao, A., Li, Y., Yan, Y., Qiu, Y., Li, B., Xu, W., et al. (2020). Increased prediction value of biomarker combinations for the conversion of mild cognitive impairment to Alzheimer's dementia. Transl. Neurodegener. 9:30. doi: 10.1186/s40035-020-00210-5

Zhao, Y., Haney, M. J., Gupta, R., Bohnsack, J. P., He, Z., Kabanov, A. V., et al. (2014). GDNF-transfected macrophages produce potent neuroprotective effects in Parkinson's disease mouse model. PLoS One 9:e106867. doi: 10.1371/journal. pone.0106867

Zhou, W., Fong, M. Y., Min, Y., Somlo, G., Liu, L., Palomares, M. R., et al. (2014). Cancer-secreted mir-105 destroys vascular endothelial barriers to promote metastasis. Cancer Cell 25, 501-515. doi: 10.1016/j.ccr.2014.03.007

Zhuang, X., Xiang, X., Grizzle, W., Sun, D., Zhang, S., Axtell, R. C., et al. (2011). Treatment of brain inflammatory diseases by delivering exosome encapsulated anti-inflammatory drugs from the nasal region to the brain. Mol. Ther. 19, 1769-1779.

Conflict of Interest: The authors declare that the research was conducted in the absence of any commercial or financial relationships that could be construed as a potential conflict of interest.

Publisher's Note: All claims expressed in this article are solely those of the authors and do not necessarily represent those of their affiliated organizations, or those of the publisher, the editors and the reviewers. Any product that may be evaluated in this article, or claim that may be made by its manufacturer, is not guaranteed or endorsed by the publisher.

Copyright (c) 2022 Duggan, Lu, Foster, Wimmer and Parikh. This is an open-access article distributed under the terms of the Creative Commons Attribution License (CC BY). The use, distribution or reproduction in other forums is permitted, provided the original author(s) and the copyright owner(s) are credited and that the original publication in this journal is cited, in accordance with accepted academic practice. No use, distribution or reproduction is permitted which does not comply with these terms. 